NASA TECHNICAL NOTE

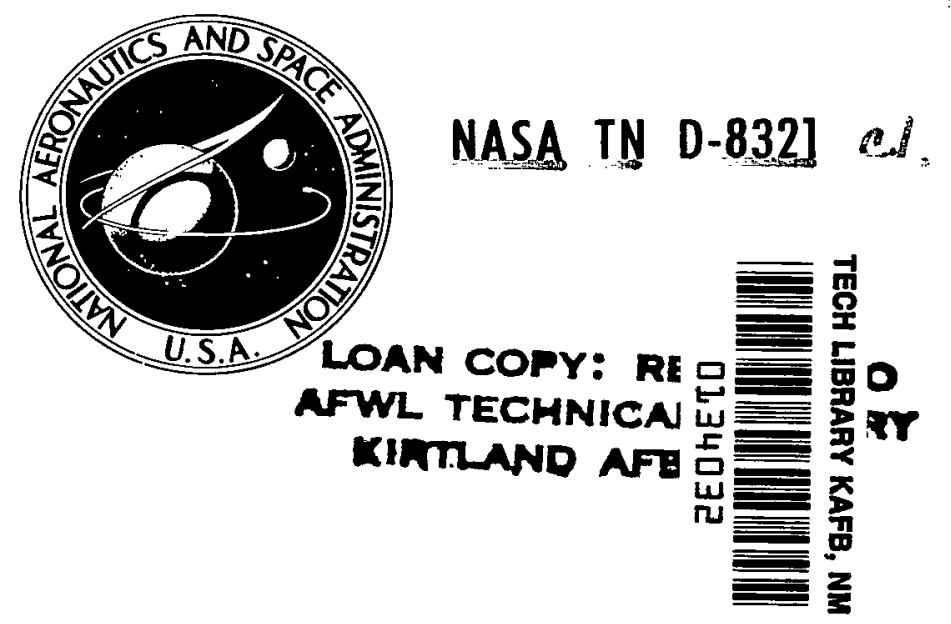

REMOTE SENSING OF SOIL MOISTURE WITH MICROWAVE RADIOMETERS-II

T. Schmugge, T. Wilbeit, $W$. Webster, Jr., and P. Gloersen

Goddard Space Flight Center Greenbelt, Md. 20771

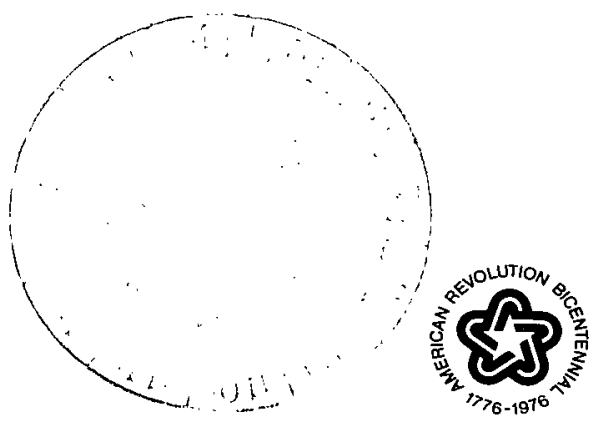

national aeronautics and SPACE administration - WaShington, D. C. - SEPtember 1976 
0134032

$\mid$\begin{tabular}{l|} 
1. Report No. \\
NASA TN D-8321 \\
4. Title ond Subtifle \\
Remote Sensing of Soil Moisture with Microwave \\
Radiometers-II \\
7. Author(s) \\
T. Schmugge, T. Wilheit, W. Webster, Jr, and P. Gloersen \\
9. Performing Organi zation Name and Address \\
Goddard Space Flight Center \\
Greenbelt, Maryland 20771 \\
12. Sponsoring Agency Nome ond Address \\
National Aeronautics and Space Administration \\
Washington, D.C. 20546
\end{tabular}

3. Recipient's Catalog No.

\section{Report Date}

September 1976

6. Performing Organization Code 913

8. Performing Organizatian Report No. G-76114

10. Work Unit No. $177-51-41$

11. Controct or Gront Mo.

13. Type of Report and Period Covered

Technical Note

15. Supplementary Notes

14. Sponsoring Agency Code

16. Abstract

The results presented here are derived from measurements made by microwave radiometers during the March 1972 and February 1973 flights of National Aeronautics and Space Administration (NASA) Convair-990 aircraft over agricultural test sites in the southwestern part of United States. The purpose of the missions was to study the use of microwave radiometers for the remote sensing of soil moisture. The microwave radiometers covered the $0.8-$ to $21-\mathrm{cm}$ wavelength range. The results show a good linear correlation between the observed microwave brightness temperature and moisture content of the 0 - to $1-\mathrm{cm}$ layer of the soil. The results at the largest wavelength $(21 \mathrm{~cm})$ show the greatest sensitivity to soil moisture variations and indicate the possibility of sensing these variations through a vegetative canopy. The effect of soil texture on the emission from the soil was also studied and it was found that this effect can be compensated for by expressing soil moistures as a percent of field capacity for the soil. The results are compared with calculations based on a radiative transfer model for layered dielectrics and the agreement is very good at the longer wavelengths. At the shorter wavelengths, surface roughness effects are larger and the agreement becomes poorer.

17. Key Words (Selected by Author(s)) Remote sensing, Soil moisture, Microwave radiometers, Soil texture, Layered dielectrics

19. Security Classif. (of this report)

Unclassified
18. Distribution Statement

Unclassified-Unlimited

Cat. 43

20. Security Classif. (of this poge) Unclassified

\begin{tabular}{|c|c|}
\multicolumn{2}{|c|}{ Cat. 43} \\
\hline 34 & $\$ 3.75$ \\
\hline
\end{tabular}

For sale by the National Technical Information Service, Springfield, Virginia 22161 
This document makes use of international metric units according to the Systeme International d'Unites (SI). In certain cases, utility requires the retention of other systems of units in addition to the SI units. The conventional units stated in parentheses following the computed SI equivalents are the basis of the measurements and calculations reported. 


\section{CONTENTS}

Page

ABSTRACT. . . . . . . . . . . . . . . . . . . i

INTRODUCTION . . . . . . . . . . . . . . . . . . . . . . . . 1

BACKGROUND . . . . . . . . . . . . . . . . . . . . . . . . . 2

EXPERIMENTAL DETAILS . . . . . . . . . . . . . . . . . 6

RESULTS . . . . . . . . . . . . . . . . . . . . . . 11

DISCUSSION . . . . . . . . . . . . . . . . . . . . . 14

CONCLUSION ........................ . . . . 18

ACKNOWLEDGMENTS . . . . . . . . . . . . . . . . . . 18

REFERENCES ...................... . . 33 


\title{
REMOTE SENSING OF SOIL MOISTURE WITH MICROWAVE RADIOMETERS-II
}

\author{
T. Schmugge, T. Wilheit, W. Webster, Jr., and P. Gloersen \\ Goddard Space Flight Center \\ Greenbelt, Maryland
}

\section{INTRODUCTION}

Interest in developing techniques for the remote sensing of soil moisture has increased significantly in recent years in response to the need for this type of data covering large areas. The information is needed in the fields of meteorology, hydrology, and agriculture. In the field of meteorology, knowledge of soil moisture is necessary for the largescale assessment of the moisture flux into the atmosphere. Knowledge of the moisture content in a surface layer about $10 \mathrm{~cm}$ thick is considered important for predicting the runoff following a rain, and the successful germination and early growth of plants. However, to predict crop yields, the moisture content in the root zone must be known. This depth is approximately $1 \mathrm{~m}$ and is probably not directly measurable by remote sensing. In addition, remotely sensed soil-moisture data would be of use in locating potential outbreaks of certain insect pests which deposit their eggs in the soil, since the subsequent development of the eggs is dependent on soil-moisture content (Reference 1).

Recent efforts have been made to correlate soil moisture with several parameters that can be remotely sensed, such as surface albedo (Reference 2), the diurnal range of surface temperature (Reference 3), microwave backscatter coefficient (Reference 4), and microwave emissivity (Reference 5).

The variation of the microwave emissivity for a soil has been studied extensively by truckmounted radiometers in fields (References 6 and 7). These measurements have indicated the sensitivity of microwave emissivity to soil moisture and the dependence of this sensitivity on surface roughness and vegetative cover. Researchers have concluded that the longer wavelength radiometers, for example $21 \mathrm{~cm}$, are preferable for the remote sensing of soil moisture. Radiometers operating at this wavelength showed lower sensitivity to the effect of surface roughness and a greater capability to sense moisture variations through a vegetative canopy than those operating at shorter wavelengths.

Aircraft observations of these effects have been made both in this country by Schmugge et al. (Reference 5) and in the Soviet Union by Basharinov et al. (Reference 8). The research performed in the United States determined a nonlinear dependence of microwave 
brightness temperature $\left(T_{B}\right)$ on soil moisture from aircraft platform observations. Little change in brightness temperature was observed at a wavelength of $1.55 \mathrm{~cm}$ for soil-moisture values less than 10 or 15 percent (depending on soil type), while above these values, a linear decrease of about $3 \mathrm{~K} / 1$ percent soil moisture was observed. The soil-moisture values reported were the average moisture contents in the top $15 \mathrm{~cm}$ of the soil, and these results indicate that the nonlinear behavior was due to the drying out of a thinner surface layer. Calculations using a radiative transfer model for layered dielectrics indicated that the observed brightness temperatures were determined by the moisture content of a surface layer only $\sim 0.1$ of a wavelength thick. In this paper, results are given from flights with the NASA Convair-990 aircraft in 1972 and 1973 which confirm that the emissivity is indeed determined by the moisture content of this layer.

\section{BACKGROUND}

The intensity of the emitted radiation is essentially proportional to the product of the temperature and emissivity of the surface. This product is commonly referred to as brightness temperature $\left(\mathrm{T}_{\mathrm{B}}\right)$. The radiation received by an airborne or spaceborne radiometer at an altitude $(\mathrm{H})$ above the ground is given by

$$
\mathrm{T}_{\mathrm{B}}=\tau(\mathrm{H}, \theta)\left[\mathrm{R} \mathrm{T}_{\mathrm{SKY}}+(1-\mathrm{R}) \mathrm{T}_{\mathrm{SURF}}\right]+\mathrm{T}_{\mathrm{ATM}}(\mathrm{H}, \theta)
$$

where $\tau$ is the atmospheric transmission and $\mathrm{R}$ is the surface reflectivity. A schematic is presented in figure 1 . The three terms of the equation represent the three sources of the observed radiation: first, reflected sky brightness $\left(\mathrm{T}_{\mathrm{SKY}}\right)$; second, the thermal emission from the surface $\left(\mathrm{T}_{\text {SURF }}\right)$; and third, the emission from the intervening atmosphere $\left(\mathrm{T}_{\mathrm{ATM}}\right)$. The factor $\tau$ is atmospheric absorption of the radiation coming from the surface. For the lowaltitude observations reported in this paper, the atmospheric effects are negligible as will be shown later. Thus, we can concentrate on the surface term. The quantity $(1-R)$ is the emissivity for the surface. The large variation at microwave wavelengths of this quantity for terrestrial surfaces causes the major variations in the observed brightness temperature.

The large dielectric constant of liquid water produces most of this variation in the surface emissivity. The real and imaginary parts of the dielectric constant of pure water at $20^{\circ} \mathrm{C}$ are plotted in figure 2 for the 100 - to $0.1-\mathrm{cm}$ wavelength range. These data are based on the measurements of Lane and Saxton (Reference 9). In this region of the spectrum, the real part decreases from about 80 at $100 \mathrm{~cm}$ to less than 10 at $0.1 \mathrm{~cm}$. The imaginary part reaches its maximum around $1.5 \mathrm{~cm}$ where the real part is changing most rapidly.

Most dry soils have dielectric constants of about 3 for the real part and less than 0.01 for the imaginary part. The addition of water causes marked changes in the dielectric properties. Figure 3 contains data on the variation of these dielectric properties with moisture content at two wavelengths $-21 \mathrm{~cm}$ (Reference 10) and $1.55 \mathrm{~cm}$. These measurements were made on two soils having very similar textures, that is, particle-size distribution. Thus, the differences between the two sets of measurements arise from the wavelength 
difference. This results from the differences in the dielectric properties of water at these two wavelengths, that is, for wet soils the real part is larger at $21 \mathrm{~cm}$ while the imaginary part is larger at $1.55 \mathrm{~cm}$. The resultant emissivities have been calculated, assuming a uniform dielectric medium, from the Fresnel equation (Reference 11). The range of emissivity from dry to wet was 0.94 to 0.50 at $21 \mathrm{~cm}$ and 0.95 to 0.60 at $1.55 \mathrm{~cm}$. Thus, observations at the longer wavelengths would have greater sensitivity to soil-moisture variations.

It can be further seen in figure 3 that the addition of water has very little effect on the dielectric properties of the soil at low-moisture contents ( $\leqslant 10$ percent). Presumably this is due to the interaction of the water molecules with the soil particles which reduces the polarizability of the water in a thin layer around each particle. The frequency variation of the dielectric constants for a silty clay soil with a similar moisture content has been observed by Hoekstra and Delaney (Reference 12). The curves have shapes similar to those of water (figure 2), but the peak of the imaginary curve occurs at allower frequency, between 1 and $2 \mathrm{GHz}$. They were able to fit the soil data with a modified Debye equation containing two terms. One term has a characteristic relaxation frequency of $1.5 \mathrm{GHz}$ and is representative of the bound water, and the second has a relaxation frequency of $20 \mathrm{GHz}$ which is roughly that of free water. As the water content of the soil increases, one would expect that the free-water term would become dominant. Unfortunately, Hoekstra and Delaney were not able to perform their measurements at water contents greater than 15 percent by weight. Thus, they did not get into the region of moisture content for clay soils where the soil water has its largest dielectric effect (the region of steepest slope in figure 3 ).

At $1.4 \mathrm{GHz}$, Lundien (Reference 10) has observed that the dielectric constant versus the soilmoisture curve can be approximated by two straight lines, and that their intersection is a linearly increasing function of the fraction of particles finer than $0.02 \mathrm{~mm}$ in the soil. The intersection for a sand was at 7 percent and for a heavy clay at 21 percent. Thus, the dielectric properties of a soil are dominated by the amount of free water in the soil, which in turn is related to the soil texture.

The lines in figure 3 are linear regression fits to the data in the region represented by each line. These regression results will be used in calculations discussed later in this document.

Since the thermally emitted microwave energy originates within the volume of the soil and not at the surface, the term $(1-R) T_{\text {SURF }}$ is a simplification of the actual situation because it assumes a uniform temperature throughout the emitting medium. Therefore, this term should be an integral over the entire thickness of the soil under consideration, that is,

$$
(1-R) \mathrm{T}_{\mathrm{SURF}}=(1-\mathrm{R}) \int_{\infty}^{0} \mathrm{~T}(\mathrm{z}) \mathrm{a}(\mathrm{z}) \exp -\left(\int_{\mathrm{z}}^{0} \mathrm{a}(\mathrm{x}) \mathrm{dx}\right) \mathrm{dz}
$$


where $T(z)$ and $a(z)$ represent the subsurface temperature and absorption coefficient profiles, respectively. Wilheit (Reference 13) has developed a model in which the integral is replaced, by a sum over many layers:

$$
(1-R) T_{S U R F}=\sum f_{i} T_{i}
$$

where $f_{i}$ is the fraction of the radiation incidence on the air-soil interface that would be absorbed in the $i$ th layer and $T_{i}$ is the temperature of this layer. The values of $f_{i}$ are determined by applying the electromagnetic boundary conditions to determine the electric fields above and below each interface. These fields are then used to determine the energy fluxes entering and leaving each layer. The computations indicate that the radiation from the soil is characterized by two sampling depths: reflective and thermal. The reflectivity is characterized by changes in the real part of the index of refraction over a sampling depth: $\delta_{r} \simeq 0.1 \lambda$, where $\lambda$ is the wavelength in the medium. The thermal sampling depth is determined by the losses deeper in the medium, and is given by

$$
\delta_{T}=\frac{\sum \mathrm{x}_{\mathrm{i}} \mathrm{f}_{\mathrm{i}}}{\sum \mathrm{f}_{\mathrm{i}}}
$$

where $x_{i}$ is the depth of the ith layer. For a uniform dielectric this reduces to

$$
\delta_{T}=\frac{\lambda}{4 \pi \operatorname{Im}(\mathrm{n})}
$$

For a low-loss dry soil, $\delta_{\mathrm{T}}$ will be an order of magnitude larger than $\delta_{\mathrm{r}}$, while for a wet soil, it will be only slightly larger.

Another parameter of interest is the average soil temperature over this thermal sampling which is given by

$$
\mathrm{T}_{\mathrm{AV}}=\frac{\sum \mathrm{T}_{\mathrm{i}} \mathrm{f}_{\mathrm{i}}}{\sum \mathrm{f}_{\mathrm{i}}}
$$

where $T_{i}$ is the physical temperature of the $i$ th layer. The ratio of $T_{B}$ to $T_{A V}$ is an effective emissivity for the soil.

The soil-moisture information of the most interest is the amount of water in the soil which is not tightly bound to the soil particles. This water can freely evaporate from the soil and is readily absorbed by plants. The data presented in this report indicate that the emissivity of soil is lowered only when the soil water is not bound. The reason for this is that the tightly bound water does not have the same dielectric properties as free water and, more importantly, it can only move into the surface layer of the soil very slowly. This movement is largely in the vapor phase and occurs as a result of alternate condensation and evaporation on the 
particle surfaces. Only when moisture is in the surface layer of the soil can it affect the microwave emission from the soil.

The state of the water in the soil is described by the pressure potential. At low-moisture levels, the pressure potential is the tension with which water is held by soil particles. In the intermediate range, the pressure potential is determined largely by the radii of curvature of water films between soil particles. In figure 4, representative plots of the relation between volumetric water content and pressure potential are presented (Reference 3 ). The zero potential level is the saturated soil situation. The locations of the $-1 / 3$-bar and -15 -bar pressure levels are indicated because they are frequently taken to be the pressure levels for the field capacity (FC) and wilting point (WP) conditions of the soil. This convention will be followed here. The amount of water in the soil at field capacity is that which remains in a soil two or three days after having been saturated and after free drainage has practically ceased. As the name implies, the wilt point is the moisture level at which plants experience difficulty drawing water from the soil. Thus, the FC and WP soil-moisture values give a quantitative measure of the water-holding capacity of a soil. The difference between the two is the available water capacity in the soil. As the curves in figure 4 indicate, FC and WP depend on soil type. The values for the four soils are presented in table 1 .

Table 1

Moisture Content of Selected Soils at WP, FC, and Saturated Conditions

\begin{tabular}{|l|c|c|c|}
\hline Soil & $\begin{array}{c}\text { WP at }-15 \text { bar } \\
\left(\mathrm{cm}^{3} / \mathrm{cm}^{3}\right)\end{array}$ & $\begin{array}{c}\text { FC at }-1 / 3 \text { bar } \\
\left(\mathrm{cm}^{3} / \mathrm{cm}^{3}\right)\end{array}$ & $\begin{array}{c}\text { Saturation at 0 bar } \\
\left(\mathrm{cm}^{3} / \mathrm{cm}^{3}\right)\end{array}$ \\
${ } }$ & 0.22 & 0.35 & 0.70 \\
Cashion Silty Clay & 0.22 & 0.33 & 0.50 \\
Avondale Loam & 0.11 & 0.25 & 0.44 \\
Gran Sandy Loam & 0.06 & 0.15 & 0.36 \\
\hline
\end{tabular}

Thus, the available water capacity of the clay soils is no greater than that of the Avondale Loam, even though the magnitudes are much greater.

Since it would be very difficult to obtain|curves like those in figure 4 for the soils in all the sampled fields, we attempted to relate FC and WP to the soil textures of the sampled fields. This was based on the work of Salter and Williams (Reference 14) who studied the use of regression analysis to relate particle-size composition (soil texture) to the available water capacity for a soil. They concluded that the moisture characteristics could be calculated from texture information with reasonable accuracy; that is, the upper and lower limits of available water capacity could be estimated to within 10 or 20 percent of the measured values. Therefore, a multiple linear regression analysis was made on 100 sets of soil textures and moisture characteristics, that is, the moisture contents at the $-1 / 3-\mathrm{bar}(\mathrm{FC})$ and 
-15-bar (WP) potentials. These measurements were made on soils from the Phoenix area (Private communication, Phoenix Soil Conservation Office, 1974) and from the Rio Grande Valley of Texas (Reference 15). The range of textures included in the regression covered those observed in the fields. The results of the regression for WP, expressed in weight percent, were

$$
\mathrm{WP}=7.2-0.07 \times \mathrm{SAND}+0.24 \times \mathrm{CLAY}
$$

where SAND and CLAY represent their respective soil fractions in percent. The multiple correlation coefficient for this regression was 0.945 . The regression results for $\mathrm{FC}$ are

$$
\mathrm{FC}=25.1-0.21 \times \mathrm{SAND}+0.22 \times \mathrm{CLAY}
$$

with a multiple correlation coefficient of 0.904 . The coefficient of variation (standard estimate of error divided by the mean) was 0.15 for both of these regressions. The moisture characteristics of a soil depend on many factors in addition to soil texture, such as bulk density of the undisturbed soil and percent organic matter, but texture (sand, silt, and clay fractions) was the only parameter that could easily be determined for all of the soils involved. It is presumed basing the regression on the actual field soils used in the soil surveys adequately takes these factors into account.

The effect of a vegetative canopy over the soil will be that of an additional dielectric layer, the mixture of plant matter and air, between the radiating soil and the radiometer. Sibley (Reference 16) has estimated the dielectric constant for this layer using a Weiner mixing formula and found that a canopy with a height density product of $4 \mathrm{~cm}$ (that is, 20-cm high wheat with 20 percent of the volume containing plant matter) increased the brightness temperature above that expected for a bare, moist soil by $5 \mathrm{~K}$ at $1 \mathrm{GHz}, 40 \mathrm{~K}$ at $3 \mathrm{GHz}$, and $70 \mathrm{~K}$ at $5 \mathrm{GHz}$. Field measurements at $1.42 \mathrm{GHz}$ (Reference 7) have qualitatively supported this result.

\section{EXPERIMENTAL DETAILS}

The flights described in this report were flown in March 1972 and February 1973. The aircraft used in the experiment was the NASA Convair-990. The test sites were the agricultural areas around Phoenix, Arizona and Imperial Valley, California. The times of the individual flights and the meteorological conditions at each site are described in table 2 . The altitude for all the data flights was $0.6 \mathrm{~km}$ above the ground with a ground speed of 110 to $120 \mathrm{~m} / \mathrm{s}$. At this altitude, the effects of the atmosphere on the observed brightness temperatures (see equation 1) are minimal for all of the wavelengths considered in this report, as indicated in table 3.

These calculations were performed using an atmospheric profile obtained from the nearest rawinsonde station (Tucson). This was a dry atmosphere with 12-percent relative humidity 
Table 2

Description of Data Gathering Flights

\begin{tabular}{|c|c|c|c|}
\hline Date & Site & $\begin{array}{c}\text { Local } \\
\text { Standard Time }\end{array}$ & Meteorological Conditions \\
\hline March 7, 1972 & $\begin{array}{l}\text { Phoenix, Arizona } \\
100 \text { fields }\end{array}$ & $14: 04$ to $14: 45$ & $\begin{array}{l}\text { Clear, } 100 \text { percent sunshine } \\
\text { Air Temperature }=31^{\circ} \mathrm{C} \\
17 \text { percent Relative Humidity }\end{array}$ \\
\hline March 11, 1972 & Phoenix, Arizona & $\begin{array}{l}12: 25 \text { to } 13: 12 \\
15: 35 \text { to } 16: 23\end{array}$ & $\begin{array}{l}0.3 \text { Cirrus layer at } 7600 \mathrm{~m} \\
\text { Air Temperature }=31.4^{\circ} \mathrm{C} \\
10 \text { percent Relative Humidity } \\
0.5 \text { Cirrus layer at } 7600 \mathrm{~m} \\
\text { Air Temperature }=32^{\circ} \mathrm{C} \\
10 \text { percent Relative Humidity }\end{array}$ \\
\hline March 11, 1972 & $\begin{array}{c}\text { Imperial Valley } \\
50 \text { fields }\end{array}$ & $\begin{array}{l}11: 00 \text { to } 11: 50 \\
17: 09 \text { to } 17: 55\end{array}$ & $\begin{array}{l}0.5 \text { Cirrus at } 7600 \mathrm{~m} \\
\text { Air Temperature }=28^{\circ} \mathrm{C} \\
21 \text { percent Relative Humidity } \\
0.5 \text { Cirra stratus at } 6700 \mathrm{~m} \\
\text { Air Temperature }=29^{\circ} \mathrm{C} \\
18 \text { percent Relative Humidity }\end{array}$ \\
\hline March 13, 1972 & Phoenix, Arizona & $13: 10$ to $13: 55$ & $\begin{array}{l}0.5 \text { Cirrus at } 7600 \mathrm{~m} \\
\text { Air Temperature }=29^{\circ} \mathrm{C} \\
11 \text { percent Relative Humidity }\end{array}$ \\
\hline February 8,1973 & $\begin{array}{l}\text { Phoenix, Arizona } \\
80 \text { fields }\end{array}$ & $13: 45$ to $14: 35$ & $\begin{array}{l}0.2 \text { Cumulonimbus at } 1700 \mathrm{~m} \\
\text { Air Temperature }=19^{\circ} \mathrm{C} \\
42 \text { percent Relative Humidity }\end{array}$ \\
\hline February 8, 1973 & $\begin{array}{c}\text { Imperial Valley } \\
50 \text { fields }\end{array}$ & $15: 28$ to $15: 47$ & No Data Available* \\
\hline
\end{tabular}

*The closest station to the Imperial Valley, Yuma, Arizona, was not operating in 1973, and therefore data are not available.

at the surface and a total of $1.1 \mathrm{~cm}$ of water in the column. The $\Delta \mathrm{T}$ values are the magnitude of the atmospheric effects for a surface reflectivity of 0.3 which would be the approximate value for a wet field. For a lower reflectivity, the $\Delta \mathrm{T}$ values would be even smaller. Thus, it is apparent that atmospheric effects are small and can be neglected. 
Table 3

Atmospheric Effects

\begin{tabular}{|c|c|c|c|c|}
\hline $\begin{array}{c}\text { Wavelength } \\
(\lambda) \\
(\mathrm{cm})\end{array}$ & $\begin{array}{c}\text { Sky Brightness } \\
\left(\mathrm{T}_{\text {sky }}\right) \\
(\mathrm{K})\end{array}$ & $\begin{array}{c}\text { Transmissivity } \\
(\tau) \\
(\mathrm{K})\end{array}$ & $\begin{array}{l}\text { Atmospheric } \\
\text { Contribution } \\
\left(\mathrm{T}_{\mathrm{ATM}}\right) \\
\text { (K) }\end{array}$ & $\begin{array}{l}\text { Net Effect } \\
\left(\Delta \mathrm{T}_{\text {atm }}\right) \\
(\mathrm{K})\end{array}$ \\
\hline 21 & $\cdot 5.0$ & 0.999 & 0.3 & 1.6 \\
\hline 6 & 5.9 & 0.998 & 0.5 & 1.9 \\
\hline 2.8 & 6.6 & 0.997 & 0.8 & 2.1 \\
\hline 1.55 & 11.7 & 0.991 & 2.7 & 3.8 \\
\hline 0.8 & 19.8 & 0.985 & 4.5 & 7.4 \\
\hline
\end{tabular}

There were two tracks flown at each site: In Arizona there was a north-south track west of the city of Phoenix, and an east-west track just south of the city. In Imperial Valley there were two east-west tracks, one at the north end of the Valley over the town of Calipatria and one at the south end over the town of Imperial. The latter track was replaced for the 1973 mission with a second one at the north end of the Valley to simplify ground truth acquisition. For the 1972 flights, ground data were acquired for approximately 100 16-hectare (ha) fields around Phoenix and 50 such fields in Imperial Valley. The details of the 1972 ground observation program are described elsewhere (Reference 17). To ensure that data were obtained over the middle of these fields, two passes were made over each flight line and the best data were used in the analysis. A different approach was taken for the 1973 flight so that only fields that were $800 \mathrm{~m}$ wide and $400 \mathrm{~m}$ long (area $=32 \mathrm{ha}$ ) were sampled, and there was only one pass over each flight line.

The average soil moisture for a field was determined for depth intervals of 0 to $1 \mathrm{~cm}$ (where possible), 0 to $2.5 \mathrm{~cm}, 0$ to $5 \mathrm{~cm}$. and 0 to $10 \mathrm{~cm}$ (1972 flights only). The averages were obtained using samples from four locations in each field. The four samples for each depth were combined and the resultant soil moisture was determined gravimetrically. The soilmoisture values presented in this document are expressed on a dry-weight basis. The sampling in Imperial Valley was done by the John D. Hess Testing Corporation, and around Phoenix, by personnel from the Salt River Project. For the 1973 program, a textural analysis was performed on the soil sample obtained from each field. The soils from Imperial Valley were found to be predominantly clay loams and clays with a few sandy loam fields at the eastern edge of the Valley, while the soils from the Salt River Valley were generally not as heavy and were more evenly distributed within the range between sandy loam and clay loam. This knowledge of the soil texture enabled us to make estimates of the moisture characteristics for the soils using the regression results discussed previously in equations 7 and 8 .

For the 1972 flights, textures of the soil samples were not determined but were estimated by the field crews. In those fields sampled in both missions, the agreement between the laboratory determinations and the field estimates was very good. 
The characterization of the soil moisture for a 16- or 32-ha field by the average of only four samples introduces considerable uncertainty. The problem of the variability in soilmoisture estimates has been studied by Reynolds (Reference 18), who found that, "A sample size of 10 is usually sufficient to estimate the moisture content with a 0.1 coefficient of variation at the 95-percent probability level." While these measurements were made on $3.1 \times 1.9-\mathrm{m}$ plots for 0- to 8-cm depths, Reynolds states that the sample sizes can be taken as representative of much larger areas. More pertinent to our situation is an experiment performed by Schmugge et al. (Reference 19) on a 16-ha field south of Phoenix in which an estimate of the accuracy of the four-point measurement for a field of this size was made. This estimate is based on 36 uniformly spaced samples which were divided into four quarters with nine locations. The mean for a sample consisting of a data point from each quater of the field was calculated 100 times. The distribution of results was then compared with the overall field mean. The results for the limits of conficence at the 90-percent level are listed in table 4.

Table 4

Limits of Confidence on Ground Measurements

\begin{tabular}{|l|c|c|}
\hline $\begin{array}{l}\text { Depth } \\
(\mathrm{cm})\end{array}$ & $\begin{array}{c}\text { Field Mean } \\
\text { (percent) }\end{array}$ & $\begin{array}{c}\text { Limits } \\
\text { (percent) }\end{array}$ \\
\hline 0 to 1 & 15.8 & -2.9 to +3.5 \\
1 to 2 & 18.4 & -2.6 to +3.1 \\
2 to 5 & 21.8 & -2.5 to +2.4 \\
5 to 9 & 23.1 & -1.8 to +2.6 \\
9 to 15 & 23.9 & -1.5 to +1.7 \\
\hline
\end{tabular}

Thus, for the 0-to 1-cm layer sampled in this experiment we would expect that our measured values are within 20 percent of the actual value.

Another source of uncertainty is the time separations between the aircraft overflight and the ground measurements. Jackson et al. (Reference 20) have observed that there is a large diurnal variation in the moisture content of the surface layers, for example, $\sim 15$ percent for the 0 - to 1-cm layer three days after irrigation. The aircraft overflights occurred between noon and 3 p.m., while the ground acquisition took place over a longer time interval-all day at Imperial Valley. Therefore, those measurements made early in the morning may be 5-to 10-percent wetter for the surface centimeter than was actually the case at the time of overflight for a wet field. Fields sampled in the afternoon should be in good agreement with actual values at the time of overflight.

We have indicated the difficulties in accurately measuring the soil moisture on the ground and thus in establishing the accuracy of any remote sensing techniques. In this report, we will assume that the uncertainty in the soil-moisture value for the 0 - to $1-\mathrm{cm}$ layer is 0.2 and the uncertainty for the $0-$ to $2.5-\mathrm{cm}$ and $0-$ to $5-\mathrm{cm}$ layers is 0.15 . 
The microwave radiometers used on these flights are listed in table 5. The values for the |root-mean-square (rms) temperature sensitivity are those measured over relatively constant targets, for example, the Salton Sea or barren desert. Surface temperatures were measured during some of the flights using a nadir-viewing infrared radiometer (Reference 21) operating in the 10- to $12-\mu \mathrm{m}$ atmospheric window. In addition, a scanning infrared radiometer was used to map surface temperature variations for both series. A nadir-viewing camera was used to determine the flight path of aircraft. This film coverage was then used to determine the specific times that the aircraft was over the target fields so that radiometer data could be compared with ground measurements.

Table 5

Microwave Radiometers Used in 1972 and 1973

Soil-Moisture Flights

\begin{tabular}{|c|c|l|c|c|}
\hline $\begin{array}{c}\text { Wavelength } \\
(\mathrm{cm})\end{array}$ & $\begin{array}{c}\text { Frequency } \\
(\mathrm{GHz})\end{array}$ & Polarization & Nadir Angle & $\begin{array}{c}\text { Sensitivity } \\
(\mathrm{K})\end{array}$ \\
\hline 21.0 & 1.42 & Nadir & $0^{\circ}$ & $2.5\left(1 \mathrm{~s}^{*}\right)$ \\
6.0 & 4.99 & Vertical & $38^{\circ}$ & $2.0(1 \mathrm{~s})$ \\
6.0 & 4.99 & Horizontal & $38^{\circ}$ & $10.0(1 \mathrm{~s})$ \\
2.8 & 10.69 & Vertical & $38^{\circ}$ & $3.0(1 \mathrm{~s})$ \\
2.8 & 10.69 & Horizontal & $38^{\circ}$ & $3.0(1 \mathrm{~s})$ \\
1.55 & 19.35 & Horizontal & Scanner & $2.0(47 \mathrm{~ms})$ \\
0.81 & 37.00 & Vertical & $38^{\circ}$ & $2.4(1 \mathrm{~s})$ \\
0.81 & 37.00 & Horizontal & $38^{\circ}$ & $2.4(1 \mathrm{~s})$
\end{tabular}

The calibration stability of the radiometers was checked with the data acquired over water and desert targets, in particular the Salton Sea and the desert just east of the agricultural area in Imperial Valley. The results for the two years' flights are presented in table 6. The blanks in the table indicate that no useful data were acquired for that radiometer during that flight. The values are the averages for between 20 and $40 \mathrm{~s}$ of data. The results from the Salton Sea observations indicate that in 1972, the $21-\mathrm{cm}$ and $1.55-\mathrm{cm}$ radiometers were experiencing gain fluctuations, with those for $21-\mathrm{cm}$ radiometers being more severe. The calculated values for a smooth water surface using a salinity of $35 \mathrm{p} / \mathrm{t}$ (John D. Hess, private communication) are listed for a water temperature of $22^{\circ} \mathrm{C}$. Atmospheric effects were included, using atmospheric profiles obtained from rawinsondes launched from Tucson, Arizona. The 1973 Salton Sea results are in reasonable agreement with the calculated values. The observations over the desert areas show a high degree of consistency, and appear reasonable with the exception of $0.8-\mathrm{cm}$ results in 1972 which may be about 15 to $20 \mathrm{~K}$ too high. The variation of microwave $T_{B}$ over the desert should be less than that for the infrared because of the greater thermal sampling depth at the microwave wavelengths. These results 
Table 6

Brightness Temperatures Over Water and Desert Targets (in Kelvin)

\begin{tabular}{|c|c|c|c|c|c|c|c|c|c|c|}
\hline & & & & \multirow{2}{*}{\multicolumn{7}{|c|}{ Salton Sea Results }} \\
\hline & & & & & & & & & & \\
\hline Flight & Time (LST) & $\begin{array}{c}1.42 \\
\text { Nadir }\end{array}$ & $\begin{array}{c}4.99 \\
\text { Vertical }\end{array}$ & $\begin{array}{c}4.99 \\
\text { Horizontal }\end{array}$ & $\begin{array}{c}10.69 \\
\text { Vertical }\end{array}$ & $\begin{array}{c}10.69 \\
\text { Horizontal }\end{array}$ & $\begin{array}{l}19.35 \\
\text { Nadir }\end{array}$ & $\begin{array}{c}37 \\
\text { Vertical }\end{array}$ & $\begin{array}{c}37 \\
\text { Horizontal }\end{array}$ & IR \\
\hline $1(3 / 7 / 72)$ & $\begin{array}{l}12: 09 \\
12: 40\end{array}$ & $\begin{array}{r}104 \\
99\end{array}$ & & $\begin{array}{r}97 \\
112\end{array}$ & & $\begin{array}{l}119 \\
122\end{array}$ & $\begin{array}{l}131 \\
117\end{array}$ & $\begin{array}{l}187 \\
190\end{array}$ & $\begin{array}{l}148 \\
152\end{array}$ & $\begin{array}{l}20.7 \\
22.4\end{array}$ \\
\hline $2 \mathrm{~A}(3 / 11 / 72)$ & $\begin{array}{l}11: 02 \\
11: 32\end{array}$ & $\begin{array}{l}69 \\
40\end{array}$ & $\begin{array}{l}130 \\
126\end{array}$ & & & $\begin{array}{l}129 \\
118\end{array}$ & $\begin{array}{l}142 \\
141\end{array}$ & $\begin{array}{l}182 \\
187\end{array}$ & $\begin{array}{l}145 \\
150\end{array}$ & $\begin{array}{l}22.6 \\
25.0\end{array}$ \\
\hline $2 \mathrm{~B}(3 / 11 / 72)$ & $\begin{array}{l}17: 09 \\
17: 35\end{array}$ & $\begin{array}{l}52 \\
79\end{array}$ & $\begin{array}{l}126 \\
132\end{array}$ & & & $\begin{array}{l}118 \\
123\end{array}$ & $\begin{array}{l}108 \\
110\end{array}$ & $\begin{array}{l}196 \\
197\end{array}$ & $\begin{array}{l}155 \\
156\end{array}$ & $\begin{array}{l}25.5 \\
25.6\end{array}$ \\
\hline $1(2 / 8 / 73)$ & $\begin{array}{l}15: 27 \\
15: 42\end{array}$ & $\begin{array}{l}96 \\
92\end{array}$ & $\begin{array}{l}144 \\
148\end{array}$ & & $\begin{array}{l}138 \\
124\end{array}$ & $\begin{array}{r}102 \\
83\end{array}$ & $\begin{array}{l}119 \\
115\end{array}$ & $\begin{array}{l}169 \\
176\end{array}$ & $\begin{array}{l}129 \\
130\end{array}$ & $\begin{array}{l}16.5 \\
16.6\end{array}$ \\
\hline $\begin{array}{l}\text { Calculated } \\
\left(\mathrm{T}_{\mathrm{H}_{2} \mathrm{O}}=22^{\circ} \mathrm{C}\right)\end{array}$ & & 96 & 133 & 93 & 138 & 98 & 128 & 170 & 128 & \\
\hline \multicolumn{11}{|c|}{ Desert Results } \\
\hline $1(3 / 7 / 72)$ & $\begin{array}{l}12: 23 \\
12: 56\end{array}$ & $\begin{array}{l}274 \\
272\end{array}$ & & $\begin{array}{l}261 \\
267\end{array}$ & & $\begin{array}{l}274 \\
273\end{array}$ & $\begin{array}{l}287 \\
293\end{array}$ & $\begin{array}{l}310 \\
317\end{array}$ & $\begin{array}{l}294 \\
298\end{array}$ & 41.3 \\
\hline $2 \mathrm{~A}(3 / 11 / 72)$ & $\begin{array}{l}11: 15 \\
11: 44\end{array}$ & $\begin{array}{l}262 \\
267\end{array}$ & $\begin{array}{l}283 \\
284\end{array}$ & & & $\begin{array}{l}269 \\
270\end{array}$ & $\begin{array}{l}295 \\
299\end{array}$ & $\begin{array}{l}304 \\
310\end{array}$ & $\begin{array}{l}289 \\
294\end{array}$ & $\begin{array}{l}45.8 \\
45.7\end{array}$ \\
\hline $2 \mathrm{~B}(3 / 11 / 72)$ & $\begin{array}{l}17: 20 \\
17: 47\end{array}$ & $\begin{array}{l}273 \\
273\end{array}$ & $\begin{array}{l}281 \\
285\end{array}$ & & & $\begin{array}{l}273 \\
274\end{array}$ & $\begin{array}{l}289 \\
289\end{array}$ & $\begin{array}{l}315 \\
314\end{array}$ & $\begin{array}{l}296 \\
296\end{array}$ & $\begin{array}{l}33.8 \\
33.3\end{array}$ \\
\hline $1(2 / 8 / 73)$ & $\begin{array}{l}15: 32 \\
15: 47\end{array}$ & $\begin{array}{l}270 \\
270\end{array}$ & $\begin{array}{l}264 \\
266\end{array}$ & & $\begin{array}{l}272 \\
270\end{array}$ & $\begin{array}{l}265 \\
262\end{array}$ & $\begin{array}{l}275 \\
273\end{array}$ & $\begin{array}{l}268 \\
270\end{array}$ & $\begin{array}{l}267 \\
269\end{array}$ & $\begin{array}{l}26.5 \\
27.1\end{array}$ \\
\hline
\end{tabular}

indicate that the greatest uncertainty in our $\mathrm{T}_{\mathrm{B}}$ observations would be for the wettest fields which show low $\mathrm{T}_{\mathrm{B}}(\sim 200 \mathrm{~K})$. The greatest problem occurs for the $197221 \mathrm{-cm}$ results, where $T_{B}$ 's for the Salton Sea were as much as $50 \mathrm{~K}$ below the expected result. If the errors scale linearly from high $T_{B}$, we expect that some of the observed $T_{B}$ 's over the wet fields may be as much as $20 \mathrm{~K}$ below their actual values for the second flight. The errors for the other radiometers should be less than $5 \mathrm{~K}$ for the wet fields.

\section{RESULTS}

An example of the radiometer data is given in figure 5 . Here the infrared and 21 -cm brightness temperatures are plotted as a function of distance along the north track over Imperial Valley. This flight path is of particular interest because it includes data over the Salton Sea and the uncultivated desert east of the agricultural target area. These data indicate the range of brightness temperatures to be observed over such a combination of surfaces, that is, $96 \mathrm{~K}$ over water, 180 to $200 \mathrm{~K}$ over the wet test fields, and $280 \mathrm{~K}$ over the desert and dry fields. 
The brightness temperatures of the individual fields were determined by averaging the data acquired during the 3-s interval that the aircraft was over each field. The average brightness temperature for all the beam positions within the field was determined for the $1.55-\mathrm{cm}$ scanner. Because of the scanning it was possible to determine a $1.55-\mathrm{cm}$ brightness temperature for every field on all of the passes. Therefore, a much larger amount of data was acquired at this wavelength and will be discussed first.

\subsection{5 cm-Wavelength Radiometer Results}

Brightness temperatures for the individual fields were compared with ground measurements of soil moisture. Figure 6 gives the results for the $1.55-\mathrm{cm}$ scanning radiometer and the average soil moisture in the top centimeter for the three flights in 1972 for light soils (sandy loam and loam) and heavy soil (clay loam). The values plotted are the averages of the two passes over each field. The results for the two passes agreed within 2 or $3 \mathrm{~K}$ for the dry fields and 5 or $6 \mathrm{~K}$ for the wet fields. The standard deviations were 3 to $4 \mathrm{~K}$ for the dry, and 8 to $10 \mathrm{~K}$ for the wet, reflecting the greater variation in soil moisture expected for a wet field. The large amount of scatter in the data for the dry fields is the result of the range of surface temperature observed during the different flights. For example, there was a 15 to $20 \mathrm{~K}$ decrease in $T_{B}$ between the noon and 5 p.m. flights over Imperial Valley on March 11, 1972. The range of brightness temperature is the same for both soil types and there is a clear linear decrease of brightness temperature with soil moisture. The slope is less steep for the heavier soils because of the greater range of soil moistures that is possible for them. If the soil moisture is expressed as the percent of FC, this difference can be accounted for as shown in figure 7. Visually, the scatter in the data is somewhat smaller, and quantitatively, the correlation coefficient for these data is slightly greater than for the light and heavy soils separately. The results from the 1973 flight, presented in figure 8, support this conclusion. The scatter at low values of soil moisture is smaller because the data are from one flight only, and the magnitude is reduced by 15 to $20 \mathrm{~K}$ due to the reduced soil temperatures for the February flight date. Because of the reduced scatter at low soil moistures, it can be seen here that the decrease of $T_{B}$ did not start at zero soil moisture, but at soil moistures greater than about 25 percent of FC. The linear-regression results indicated in figure 8 are for data with soil moistures greater than 25 percent of FC. This lack of variation for low values of soil moisture is to be expected from the dielectric constant results (figure 3 ). However, the decrease in $T_{B}$ occurs at lower values of soil moisture than those at which the sharp increase in dielectric constant occurs. This may be a response to the increased moisture in the soil just below the 0-to 1-cm layer. When $T_{B}$ is compared with soil moisture for thicker layers of the soil, the flat region extends to higher values of soil moistures, for example in the 0to 2.5-cm layer, the flat region extends to 50 percent of $\mathrm{FC}$ or approximately the wilt point of the soil. In figure 9, this effect is shown in more detail. Here, $T_{B}$ values for both the 1972 and 1973 flights are compared with the excess of the soil moisture in the 0 - to $2.5-\mathrm{cm}$ layer above WP for the soil and the result is a linear decrease of $T_{B}$ with a correlation coefficient of 0.866 . 
These results confirm the concept that this radiometer is responding to the soil moisture in the top few millimeters of the soil, and that the ability of the soil to maintain a wet surface layer depends on the amount of subsurface water present-in this case, moisture above the WP in the top $2.5 \mathrm{~cm}$ of soil. Expressing the soil moisture as a percent FC for the soil also compensates for the effect of soil texture. For the remainder of the report, soil moistures will be expressed as the percent of FC for the soil.

\section{1-cm Wavelength Radiometer Results}

As indicated in figure 5 , the $21-\mathrm{cm}$ radiometer data displayed a large response to soil moisture variation. The $T_{B}$ results versus the soil moisture in the 0 - to $1-\mathrm{cm}$ layer for the two years' flights are presented in figure 10. The fact that the brightness temperature of the dry fields for the two years had approximately the same value is partially the result of the response of this radiometer to the more stable subsurface temperatures and, perhaps more significantly, the result of the instabilities observed in the performance of this radiometer in 1972. In comparing the $21-\mathrm{cm}$ results with the $1.55-\mathrm{cm}$ results, (figures 7 and 8 ), we find a greater range of $T_{B}$ observed at $21 \mathrm{~cm}$ (about $90 \mathrm{~K}$ ) than at $1.55 \mathrm{~cm}$ (about $70 \mathrm{~K}$ ) which results in a 50-percent greater slope or sensitivity to soil moisture at the longer wavelength. Here again there appears to be a region of little variation in $T_{B}$ to approximately $0.25 \mathrm{FC}$, at which point a more rapid decrease occurs. If a regression analysis is done for the data with soil moisture above $0.25 \mathrm{FC}$, the slope of the curve is increased by 20 percent, but the correlation coefficient is reduced to 0.840 due to the elimination of the dry field data for which the scatter is smaller. The effect of comparing the $21-\mathrm{cm}$ results with the soil moisture in thicker soil layers is to extend the flat region to higher soil moisture, for example to $0.5 \mathrm{FC}$ or approximately the WP of the soil for the 0 - to 2.5 -cm layer (figure 11 ). The comparison with the soil moisture in the 0 - to $5-\mathrm{cm}$ layer, figure 12 , indicates little change from the $0-$ to $2.5-\mathrm{cm}$ comparison. The poor correlations observed in figures 11 and 12 for soil moistures above $0.5 \mathrm{FC}$ undoubtedly result from the uncertainty in the soil-moisture determinations as indicated by the error bars.

\section{Off-nadir Radiometers}

The results for the vertical channel of the 6-cm radiometer are presented in figure 13. The range of $T_{B}(50$ to $60 \mathrm{~K})$ is about the same as that observed at $1.55 \mathrm{~cm}$, and the data from the two years agree very well. The decrease of $T_{B}$ begins for soil moistures greater than $\sim 0.25 \mathrm{FC}$. Unfortunately, only a small amount of data was acquired by the horizontal channel of this radiometer so that information concerning polarization effects was unobtainable.

Data from the $2.8-\mathrm{cm}$ radiometer were acquired for both polarizations during the $1973 \mathrm{flight}$ and are presented in figure 14. There is little $(\sim 5 \mathrm{~K})$ difference between the polarizations for dry soils and a 10-to 15-K difference for wet soils. These differences are much smaller than those predicted for a smooth surface, that is, approximately $50 \mathrm{~K}$ when wet and $30 \mathrm{~K}$ when dry. This decrease in polarization is due to the surface roughness of the field. Burke and Paris (Reference 22) have analyzed this problem and suggested that the effect of roughness is to make the data appear to have been acquired at a smaller nadir angle, for example 
at a nadir angle of $30^{\circ}$ instead of $49^{\circ}$ for the data they were studying. They also suggested that the average of the two polarizations should be independent of angle and thus of surface roughness. When these concepts are applied to the data in figure 14, the differences indicate a nadir angle of between $15^{\circ}$ and $20^{\circ}$ while the correlation for the average of the polarization with soil moisture is not improved over that of either channel taken separately. Also, the observed range of this average was not as great as that predicted by Burke and Paris (Reference 22), which may be due to a roughness effect that cannot be accounted for by a shift of nadir angle.

\section{Results for Vegetated Fields}

As noted earlier in this report, the effect of a vegetation canopy could be approximated by an absorbing layer above the soil. The effects of this layer were expected to be strongly dependent on wavelength, with the longer wavelengths affected least, and the experimental results proved this to be the case. In figure 15, values of $T_{B}$ observed for vegetated fields at wavelengths of 21 and $1.55 \mathrm{~cm}$ are presented. The results at $1.55 \mathrm{~cm}$ were, with a few exceptions, independent of soil moisture, while those at $21 \mathrm{~cm}$ showed only a slight difference from those for bare fields. These results were for fields with covers of small grains or alfalfa up to approximately $150-$ to $20-\mathrm{cm}$ high, that is, a light to moderate cover. In comparing $T_{B}$ values at $21 \mathrm{~cm}$ for the vegetated fields (figure 15) with the corresponding bare-field values (figure 11) it is noted that the $T_{B}$ 's for the vegetated fields are generally lower than the corresponding bare-field values at the same moisture content. We expect that this is due to the cooler soil temperatures and the more uniform moisture profiles for the vegetated fields. The latter situation occurs because the transpiring plant draws moisture from its entire root zone and not just from the surface soil as is the case for evaporation from bare soils. As a result, the surface layer of the soil does not become as dry as that for a bare field. Thus a $21-\mathrm{cm}$ radiometer can sense soil-moisture variations on grasslands or other areas of moderate vegetative cover.

\section{DISCUSSION}

Calculations using the layered model were performed using moisture and temperature profiles observed by the personnel at the U.S. Water Conservation Laboratory at Phoenix (Reference 23). The soil moisture and temperature profiles were observed at frequent intervals after a heavy irrigation on March 2, 1971. The data from the same area at same time of year were assumed to be reasonable estimates of the situations occurring during the aircraft overflights. It should be noted that the moisture and temperature profiles had been obtained from a smooth field, while the microwave radiometer results were obtained from rough-surfaced fields. The moisture profiles used in the calculations are presented in figure 16. The calculations were performed on predawn $(6: 30 \mathrm{a} . \mathrm{m}$.) profiles and for the early afternoon (1:30 p.m.) profiles of the same day. The corresponding temperature profiles are presented in figure 17 . These profiles are probably quite representative of the actual situation for the 1972 flights. For the 1973 flights, occurring early in February, the actual temperatures may be somewhat cooler. 
The dielectric constants used in the calculation at $\lambda=21$ and $1.55 \mathrm{~cm}$ were those presented in figure 3. These data were chosen because these soils had textures closest to that of the Avondale Clay loam soil at the Phoenix laboratory. The dielectric constants were expressed by the linear regression fits indicated in figure 3 . They were for $\lambda=21 \mathrm{~cm}$.

$$
\begin{aligned}
\text { RP } & =2.56+0.30 \times \mathrm{SM}, \mathrm{SM}<11.5 \% \\
& =-9.90+1.30 \times \mathrm{SM}, \mathrm{SM}>11.5 \% \\
\text { IP } & =0.06 \times \mathrm{SM}, \mathrm{SM}<11.5 \% \\
& =-1.44+0.185 \times \mathrm{SM}, \mathrm{SM}>11.5 \%
\end{aligned}
$$

and for $\lambda=1.55 \mathrm{~cm}$

$$
\begin{aligned}
\mathbf{R P} & =2.64+0.11 \times \mathrm{SM}, \mathrm{SM} \leqslant 7.1 \% \\
& =-2.1+0.78 \times \mathrm{SM}, 7.1 \leqslant 19.0 \% \\
& =7.85+0.25 \times \mathrm{SM}, \mathrm{SM}>19.0 \% \\
\mathrm{IP} & =0.08+\mathrm{SM}, \mathrm{SM}<10.3 \% \\
& =-5.1+0.59 \times \mathrm{SM}, 10.3 \leqslant \mathrm{SM} \leqslant 19.0 \% \\
& =0.26+0.29 \times \mathrm{SM}, \mathrm{SM} \geqslant 19.0 \%
\end{aligned}
$$

where RP and IP are the real and imaginary parts of the dielectric constant and SM is the soil moisture. The calculated values of $T_{B}$, the thermal sampling depth (equation 4), and average soil temperature (equation 6 ) for the 18 profiles are presented in table 7 . The calculated $\mathrm{T}_{\mathrm{B}}$ 's are plotted versus the average soil moisture in the 0 - to $1-\mathrm{cm}, 0-$ to $2.5-\mathrm{cm}, 0-$ to $5-\mathrm{cm}$, and 0 - to $10-\mathrm{cm}$ layers of each profile and in figures $18(\lambda=21 \mathrm{~cm})$ and $19(\lambda=1.55 \mathrm{~cm})$. These results exhibit the same type of behavior as the aircraft observations, that is, an approximately linear decrease of $T_{B}$ versus the 0. to $1-\mathrm{cm}$ soil moisture, and an essentially flat region at low soil moistures when $T_{B}$ is plotted versus the soil moisture in the 0 - to $2.5-\mathrm{cm}, 0$ - to $5-\mathrm{cm}$, and $0-$ to $10-\mathrm{cm}$ layers. These $T_{B}$ values are plotted as the $X$ 's in figures 10,11 , and 12 , containing the aircraft results. The agreement at low and moderate soil moistures is very good, while at high soil moistures the calculated values are lower than the observed values. This is perhaps a result of the combined effects of the surface roughness raising the effective emissivity of the soil, and the surface moisture for the wet fields not being uniformly high, especially for the furrowed fields. The range of $T_{B}$ calculated for the dawn profiles is about $10 \mathrm{~K}$ greater than the range for the mid-day profiles. For the moist profiles this is due to the rewetting of the surface soil from below (dew formation is unlikely in the dry desert air). For the dry profiles, rewetting is not as great a factor. As a result, the $T_{B}$ 's calculated for the dawn profiles are always lower than those of the previous day.

The calculated values of $T_{B}$ at $\lambda=21 \mathrm{~cm}$ were rather insensitive to surface temperature variation. While surface temperature changed from $8.5^{\circ} \mathrm{C}$ on the morning of day 37 to $50^{\circ} \mathrm{C}$ that afternoon, there was only a $10-\mathrm{K}$ change in $\mathrm{T}_{B}$, and part of that change could be attributed to the greater moisture content in the morning. This insensitivity to surface temperature is 
Table 7

Calculated Results for Dawn and Mid-day Profiles

\begin{tabular}{|c|c|c|c|c|c|c|c|c|c|c|}
\hline & \multicolumn{2}{|c|}{$\begin{array}{c}\text { Brightness Temperature } \\
\text { (Kelvin) }\end{array}$} & \multicolumn{2}{|c|}{$\begin{array}{l}\text { Thermal Sampling Depth } \\
(\mathrm{cm})\end{array}$} & \multicolumn{2}{|c|}{$\begin{array}{l}\text { Average Temperature of Soil } \\
\text { (Kelvin) }\end{array}$} & \multicolumn{4}{|c|}{$\begin{array}{l}\text { Soil Moisture } \\
\text { (weight percent) }\end{array}$} \\
\hline & $21 \mathrm{~cm}$ & $1.55 \mathrm{~cm}$ & $21 \mathrm{~cm}$ & $1.55 \mathrm{~cm}$ & $21 \mathrm{~cm}$ & $1.55 \mathrm{~cm}$ & 0 to $1 \mathrm{~cm}$ & 0 to $2.5 \mathrm{~cm}$ & 0 to $5 \mathrm{~cm}$ & 0 to $10 \mathrm{~cm}$ \\
\hline \multirow{9}{*}{ Dawn Profiles } & 150.3 & 173.2 & 5.83 & 0.12 & 279.6 & 276.4 & 26.1 & 24.2 & 23.3 & 21.6 \\
\hline & 163.2 & 176.4 & 6.52 & 0.14 & 276.5 & 272.1 & 21.5 & 20.2 & 19.9 & 19.0 \\
\hline & 182.2 & 182.6 & 7.03 & 0.16 & 277.6 & 273.1 & 18.1 & 17.8 & 18.0 & 17.5 \\
\hline & 202.7 & 199.5 & 7.54 & 0.21 & 279.3 & 274.8 & 15.0 & 15.5 & 16.4 & 16.4 \\
\hline & 235.4 & 247.6 & 8.54 & 0.58 & 281.8 & 277.2 & 10.0 & 12.2 & 13.9 & 14.6 \\
\hline & 251.4 & 254.8 & 9.40 & 0.76 & 282.8 & 277.1 & 7.1 & 9.3 & 11.6 & 13.0 \\
\hline & 256.7 & 260.0 & 10.45 & 0.01 & 285.2 & 279.5 & 4.6 & 6.6 & 9.2 & 11.4 \\
\hline & 265.4 & 263.1 & 11.67 & 1.18 & 288.3 & 283.0 & 3.8 & 4.9 & 6.8 & 9.4 \\
\hline & 268.1 & 265.1 & 14.11 & 1.49 & 290.9 & 284.1 & 2.8 & 3.5 & 4.9 & 7.0 \\
\hline \multirow{9}{*}{$\begin{array}{l}\text { Mid-Day } \\
\text { Profiles }\end{array}$} & 173.2 & 195.6 & 6.43 & 0.15 & 289.4 & 293.9 & 20.9 & 20.3 & 20.1 & \multirow{9}{*}{$\begin{array}{r}13.9 \\
12.8 \\
11.3 \\
9.4 \\
6.2\end{array}$} \\
\hline & $\quad 202.7$ & 217.1 & 7.14 & 0.20 & 290.1 & 299.5 & 16.1 & 16.5 & 17.3 & \\
\hline & 229.4 & 275.5 & 7.78 & 0.49 & 290.7 & 301.2 & 11.0 & 13.8 & 15.6 & \\
\hline & $\quad 242.1$ & 281.2 & 8.33 & 0.66 & 291.9 & 304.2 & 8.4 & 12.0 & 14.1 & \\
\hline & 258.4 & 286.8 & 8.95 & 0.85 & 294.5 & 306.4 & 5.6 & 9.9 & 12.6 & \\
\hline & 268.3 & 287.0 & 9.57 & 1.00 & 294.7 & 305.8 & 4.4 & 8.3 & 11.2 & \\
\hline & 273.0 & 288.7 & 10.54 & 1.25 & 295.9 & 308.0 & 3.0 & 5.7 & 9.0 & \\
\hline & 276.1 & 291.1 & 11.75 & 1.49 & 296.3 & 310.3 & 2.3 & 3.8 & 6.3 & \\
\hline & 279.1 & 296.3 & 14.74 & 1.94 & 299.7 & 315.1 & 1.7 & 2.4 & 3.9 & \\
\hline
\end{tabular}


due to the rather large thermal sampling depth at the $21-\mathrm{cm}$ wavelength. The depth (equation 4) for these profiles ranged from $6 \mathrm{~cm}$ for the wettest profiles to about $15 \mathrm{~cm}$ for the day 37 profile. For this depth there is only a 3-K difference in the dawn and midday profiles. The calculation was also performed for a case with constant 2-percent soil moisture, assuming a temperature profile similar to that for day 37 . The result was $\mathrm{T}_{\mathrm{B}}=273 \mathrm{~K}$ for the constant moisture profile compared with $279 \mathrm{~K}$ for the day 37 profile. The drier field had the lower $T_{B}$, because the greater thermal sampling depth $(34 \mathrm{~cm})$ of its constant profile enabled the radiometer to respond to the cooler subsurface temperatures. This effect undoubtedly contributed to the scatter in the $T_{B}$ values observed for the very dry fields in figures 10,11 , and 12 .

The calculated $\mathrm{T}_{\mathrm{B}}$ 's at $1.55 \mathrm{~cm}$ are plotted as X's in figure 8. Qualitatively the agreement with aircraft results is good for low and moderate moistures. There is the gradual decrease of $\mathrm{T}_{\mathrm{B}}$ out to about 60 percent of $\mathrm{FC}$ and then a sharp decrease. However, the model predicts a much lower $T_{B}$ for wet fields, for example, $195 \mathrm{~K}$ at 120 percent of $\mathrm{FC}$ compared with the observed $235 \mathrm{~K}$. The sharp increase of calculated values of $\mathrm{T}_{\mathrm{B}}$ occurs between days 4 and 5 as the profile changes from being relatively uniform to one with a sharp moisture gradient below a dry surface layer (figure 16). This dry layer, which causes the sharp increase in $T_{B}$, forms a surface mulch which reduces the evaporation from the surface.

The calculated diurnal range of $T_{B}$ at $1.55 \mathrm{~cm}$ was about $30 \mathrm{~K}$, which is much greater than the range at $21 \mathrm{~cm}$. This is because the much shallower thermal sampling depth $(\sim 1.5$ to $2 \mathrm{~cm}$ ) at this wavelength causes a greater sensitivity to the surface soil temperature. The aircraft data in figure 8 are for an early February flight with a maximum infrared surface temperature of $31^{\circ} \mathrm{C}$, while calculations for the dry profile were for late March and early April days with surface temperatures of 45 to $50^{\circ} \mathrm{C}$. Thus, it appears that the aircraft observations are approximately 15 to $20 \mathrm{~K}$ higher than calculated values would be for February profiles. Similarly, the calculated values for the dry March profile are about $20 \mathrm{~K}$ below the values observed for dry fields in the March 1972 flights. This increase in effective emissivity is probably due to surface roughness effects which have not been incorporated in the model. Volume scattering does not appear to be important for the emission from soils.

It is expected that volume scattering would cause a lowering of the brightness temperature below that which would be predicted by assuming a continuous dielectric. This is the opposite of what is observed. The good quantitative agreement between the calculated and observed values at $21 \mathrm{~cm}$ indicate that the surface roughness effects are not as important at this wavelength.

The aircraft data presented here are very encouraging for the possible use of a $21-\mathrm{cm}$ radiometer system 'as a soil-moisture sensor, and they are further supported by recent satellite results. Radiometers operating at 21 and $2.16 \mathrm{~cm}$ were onboard Skylab, and one at 1.55 $\mathrm{cm}$ is still operating onboard the Nimbus-5 satellite. A sample of the data from these three instruments is presented in figure 20. The Skylab data are from a report by Eagleman and in Reference 24. The $21-\mathrm{cm}$ radiometer had a 3-dB footprint of $110 \mathrm{~km}$ on the ground, and thus was responding to the average soil moisture over a large swath. The data 
presented here are for a pass $300-\mathrm{km}$ long across north central Texas in June 1973. The greater sensitivity of the $21-\mathrm{cm}$ radiometer to soil moisture is demonstrated by a $45-\mathrm{K}$ range of $\mathrm{T}_{\mathrm{B}}$ compared with a $15-\mathrm{K}$ range at a wavelength of $2.16 \mathrm{~cm}$ and essentially no variation at $1.55 \mathrm{~cm}$. If there had been recent rains and a considerable amount of bare ground, the $1.55-\mathrm{cm}$ data would have contained significantly lowered values of $T_{B}$ (Reference 19). Thus it would appear that the $21-\mathrm{cm}$ radiometer is responding to soil-moisture variations and it is probable that it is responding through vegetative cover. It is interesting to note that the highest values of $T_{B}$ observed at $21 \mathrm{~cm}$ were in the same range $(270 \mathrm{~K}$ to $280 \mathrm{~K}$ ) as our aircraft observations. The lowest values $(230 \mathrm{~K})$ were considerably warmer than our aircraft results $(\sim 190 \mathrm{~K})$. This is undoubtedly due to the large footprint of the Skylab radiometer averaging over a range of surface conditions. Using the data presented in figure 15 for vegetated fields, an estimate of the average soil moisture observed by the Skylab radiometer is also plotted in figure 20. The results indicate that soil moistures ranged from less than 20 percent of FC at the northwest end of the pass to about 70 percent of $\mathrm{FC}$ at the southeast end. Additional studies by McFarland (Reference 25) with the Skylab data have shown a high correlation between $21-\mathrm{cm} T_{B}$ 's and the antecedent precipitation index for this area in Texas and Oklahoma.

\section{CONCLUSION}

The results presented here have shown that the surface emissivity of a soil is determined by the dielectric properties of the surface soil layer a few tenths of a wavelength thick while the thermal sampling depths are much greater. The variation of the relationship between soil moisture and emission as a result of soil texture can be accounted for by expressing soil moisture as a percent of field capacity for the soil. The capability of the $21-\mathrm{cm}$ radiometer to sense soil-moisture variations through a moderate vegetation canopy and the promising Skylab results encourage consideration of a radiometer operating at this wavelength for routine soil moisture observations. A $21-\mathrm{cm}$ radiometer with $10-\times 10-\mathrm{m}$ antenna would have $10-\mathrm{km}$ spatial resolution from space shuttle altitudes $(400 \mathrm{~km})$. Information at this resolution would be very important in the large scale moisture budget calculations used in agricultural yield estimates, in global circulation models, and in antecedent moisture estimates for runoff predictions.

Further aircraft and field studies are necessary to refine the relationship between microwave brightness temperature and soil moisture and to quantify the effect of vegetation in more detail. The possible use of shorter wavelength radiometers, for example, $10 \mathrm{~cm}$, should also be studied because of the improved spatial resolution they would afford.

\section{ACKNOWLEDGMENTS}

We wish to thank Dr. R. Jackson and his co-workers at the U.S. Water Conservation Laboratory for providing us the unpublished temperature and moisture profile data, and Mr. Sid Wilson and his crew at the Salt River Project for their advice. We also wish to acknowledge 
the support provided by the crew of the NASA Convair-990 "Galileo" airborne observatory during these soil-moisture missions and we mourn the loss of several members of this crew in the tragic crash of that aircraft on April 12, 1973.

Goddard Space Flight Center

National Aeronautics and Space Administration Greenbelt, Maryland July 1976 

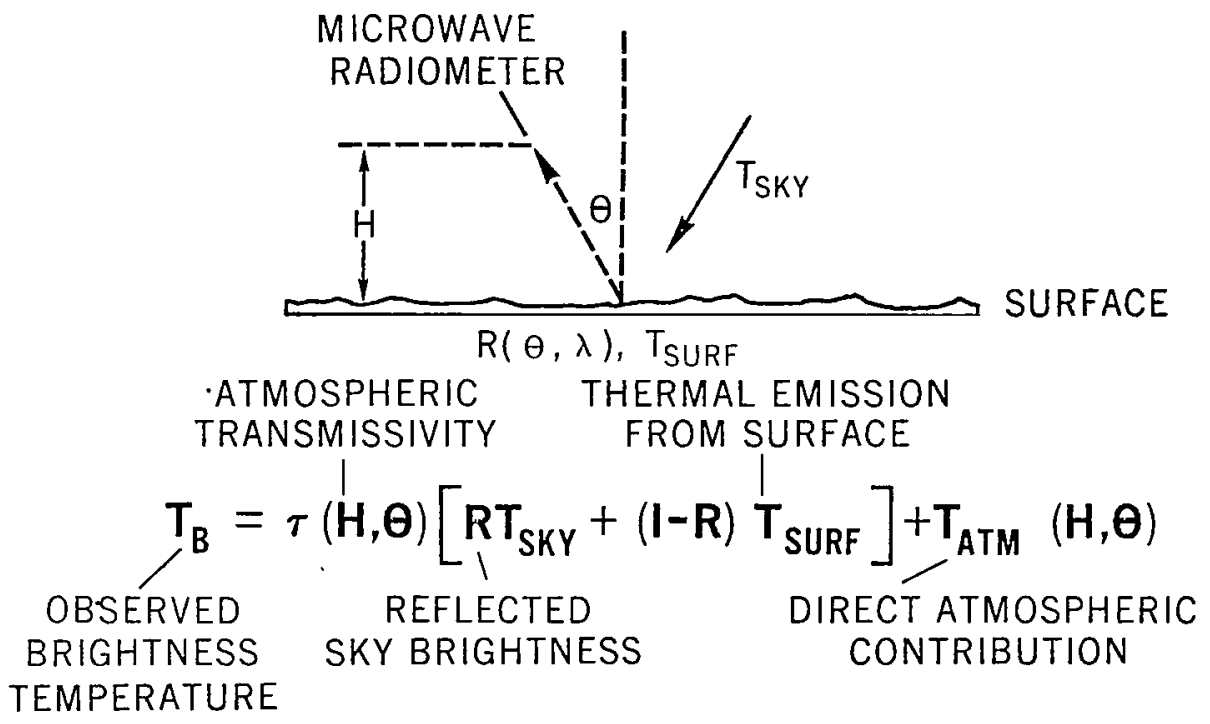

Figure 1. Schematic representation of the sources for the radiation received by a radiometer at an altitude $(\mathrm{H})$.

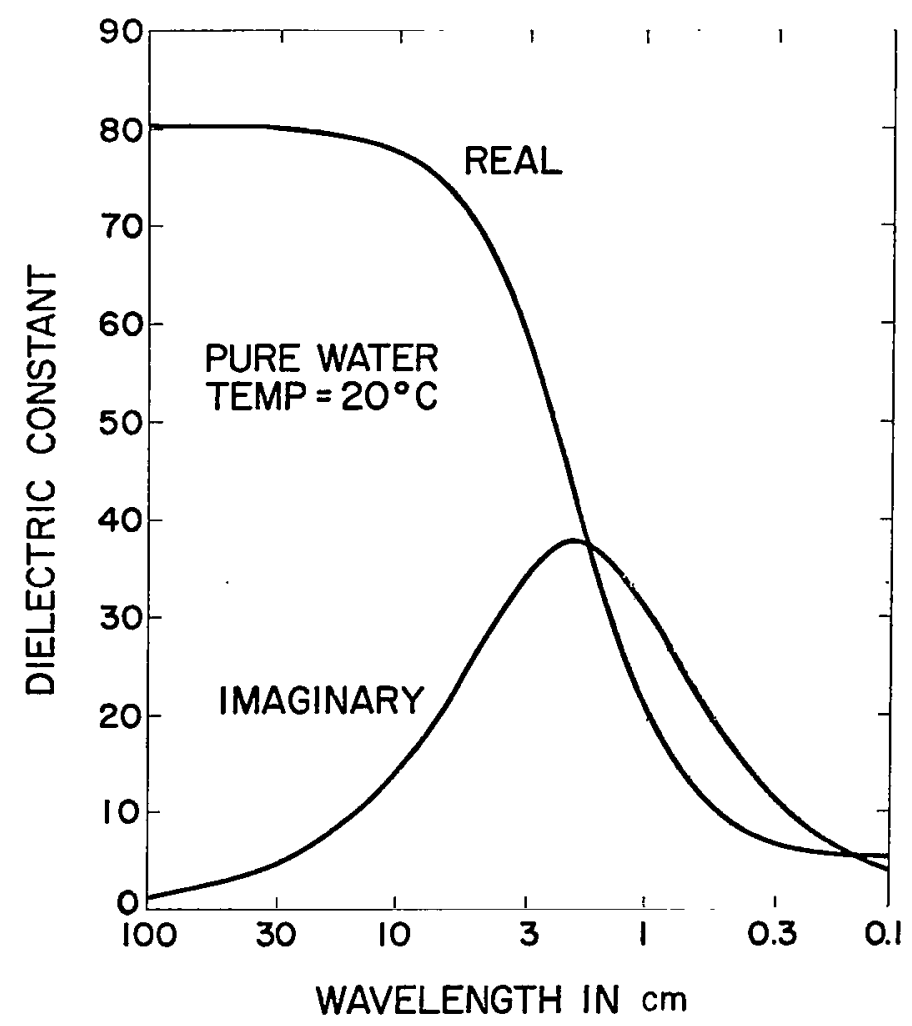

Figure 2. Real and imaginary parts of the dielectric constant of pure water at a temperature of $20^{\circ} \mathrm{C}$. 


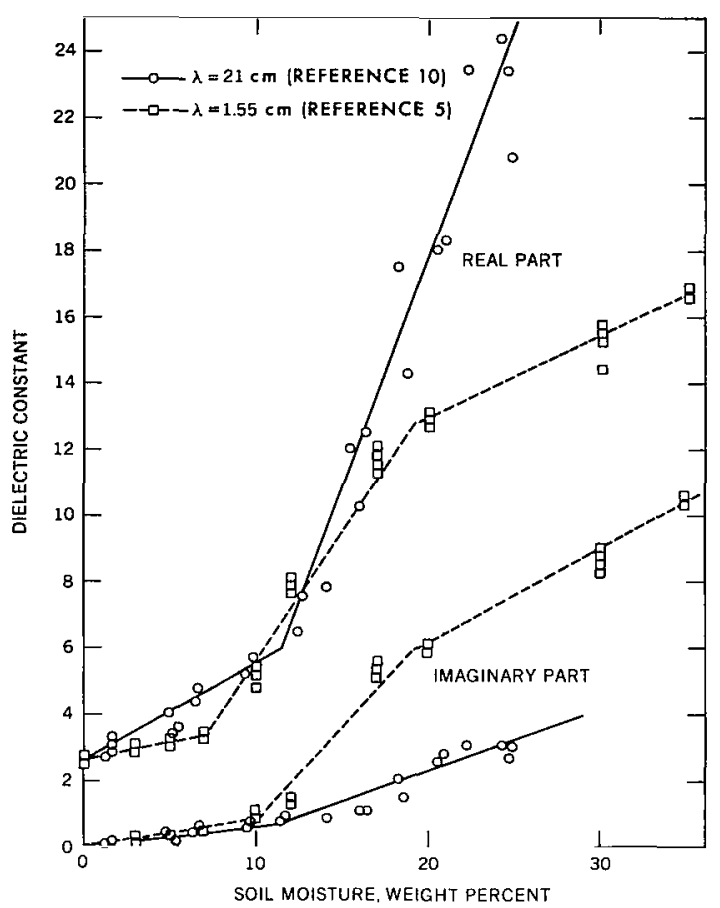

Figure 3. Real and imaginary parts of the dielectric constant for clay loam soils at wavelength of $21 \mathrm{~cm}$ (Reference 10 ) and $1.55 \mathrm{~cm}$ (Reference 5).

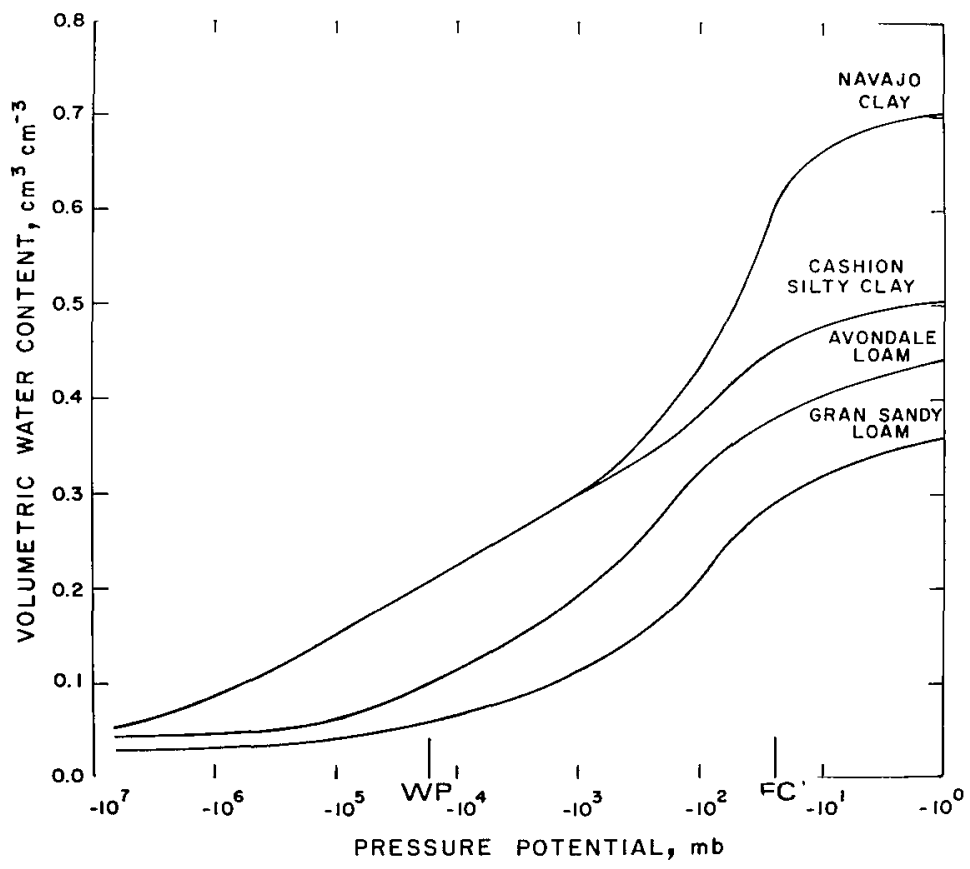

Figure 4. Volumetric soil water content versus soil water pressure potential for four different soils (Reference 3 ). 


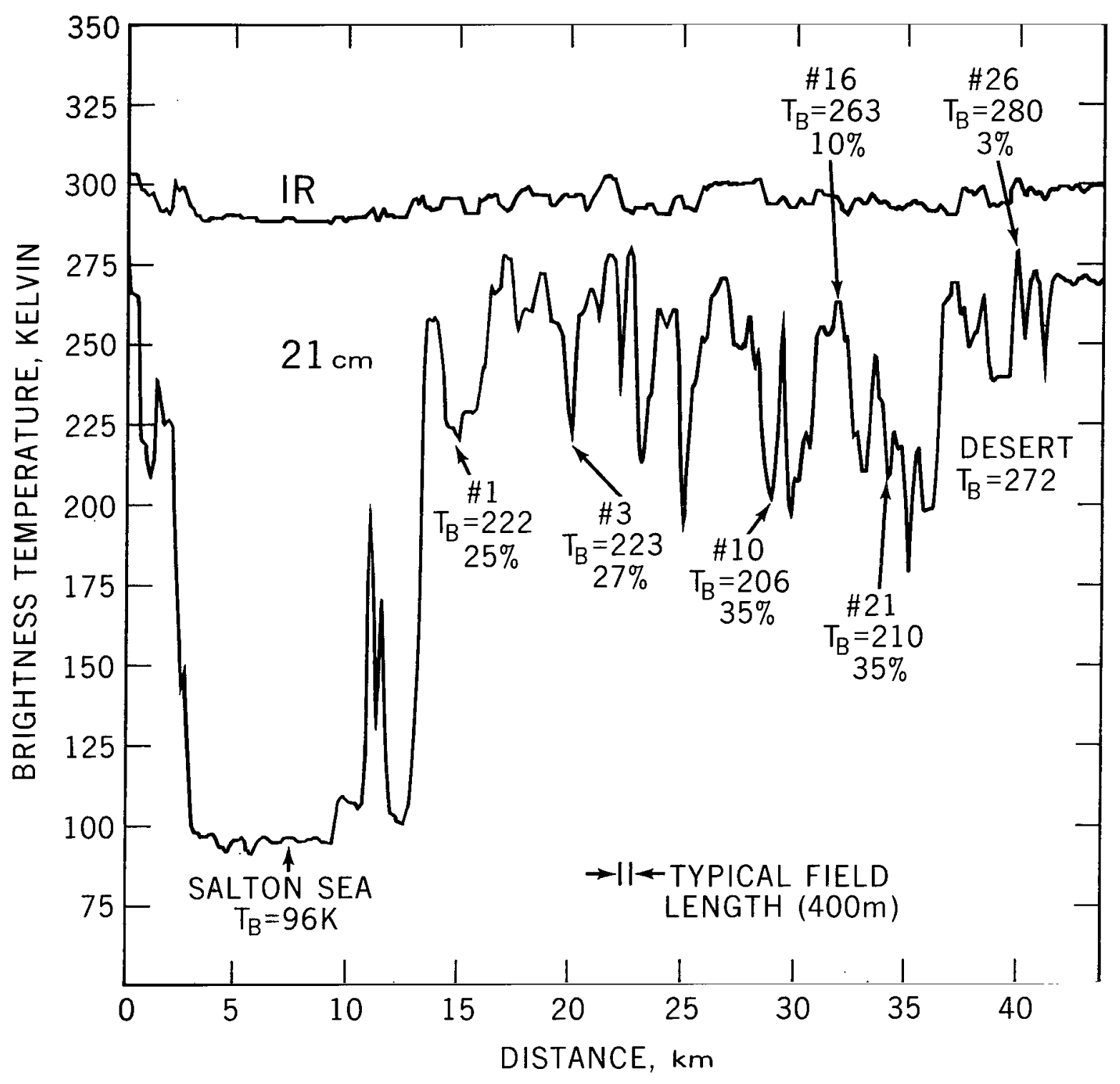

Figure 5. Thermal infrared (10-to $12-\mu \mathrm{m})$ and microwave $(21-\mathrm{cm})$ brightness temperature versus distance for a flight path at the north end of Imperial Valley. The $21-\mathrm{cm}$ brightness temperatures and measured soil moistures, are indicated for several of the fields. 


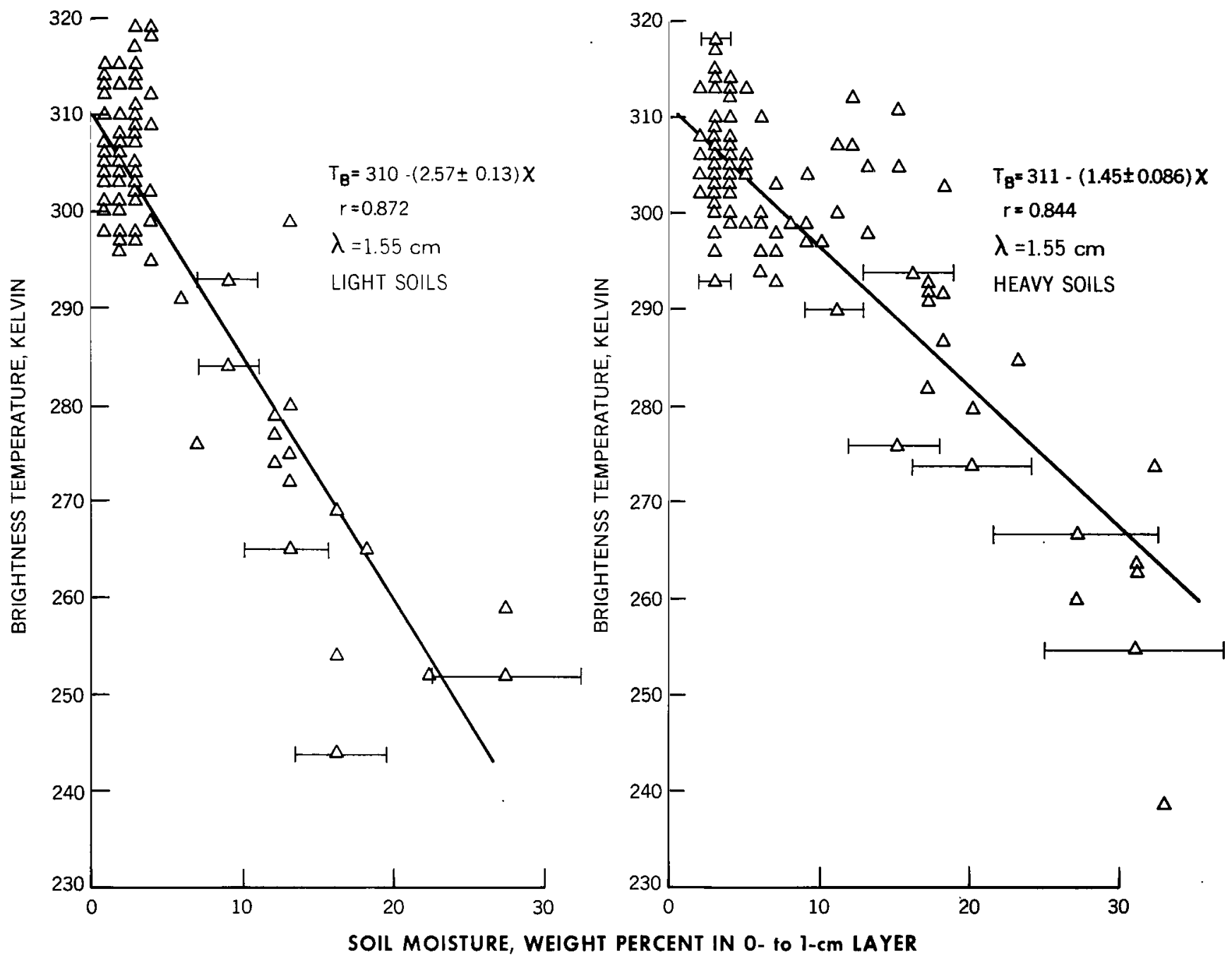

Figure 6. $1.55-\mathrm{cm}$ brightness temperatures versus soil moisture in the $0-$ to $1-\mathrm{cm}$ layer for light and heavy soils. 


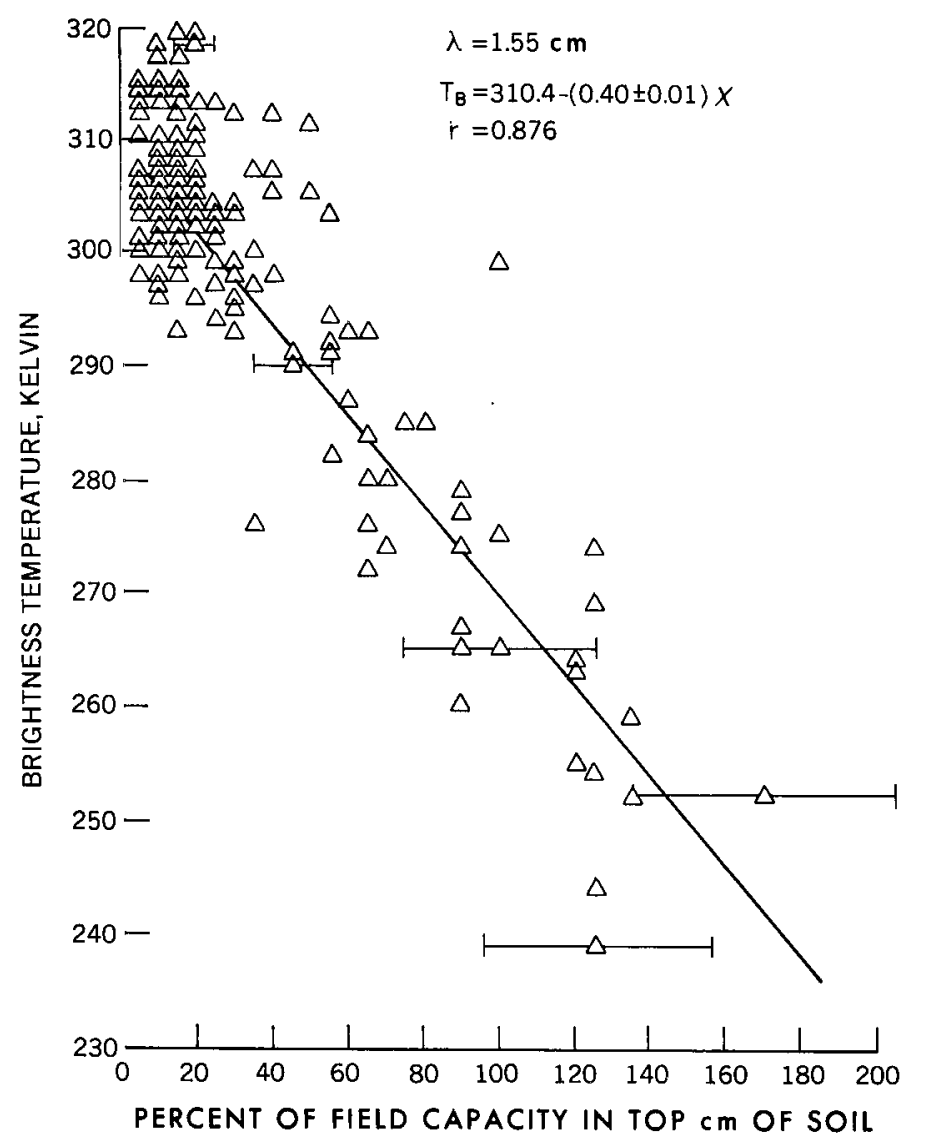

Figure 7. $1.55-\mathrm{cm}$ brightness temperatures versus percent of FC in the $0-$ to $1-\mathrm{cm}$ soil layer for the 1972 flights. The error bars indicate the uncertainty of the soil moisture measurement.

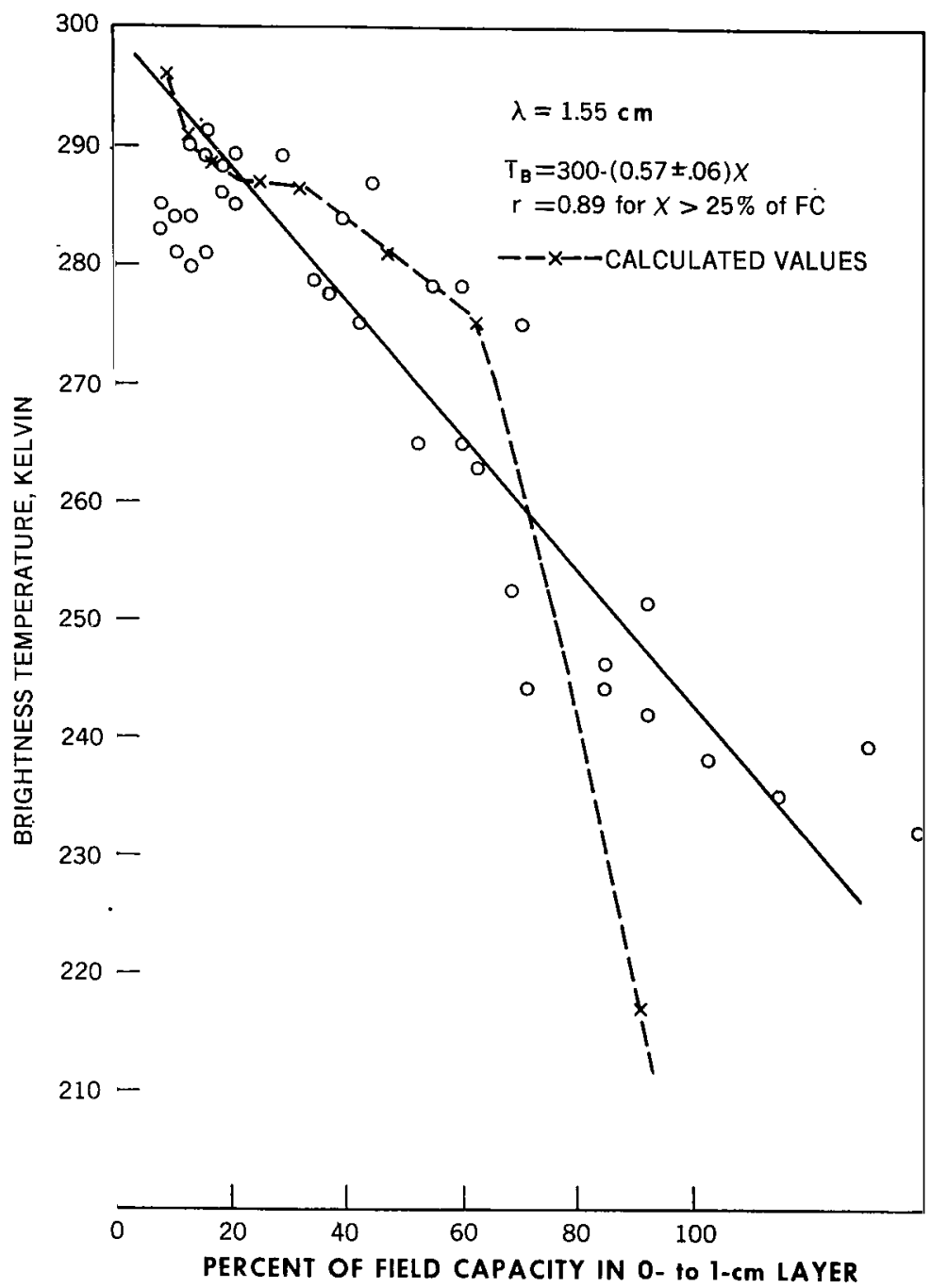

Figure 8. $1.55-\mathrm{cm}$ brightness temperature versus percent of $\mathrm{FC}$ in the 0 - to $1-\mathrm{cm}$ soil layer for the 1973 flight. The linear regression results are for the data with soil moistures greater than 25 percent of FC. 


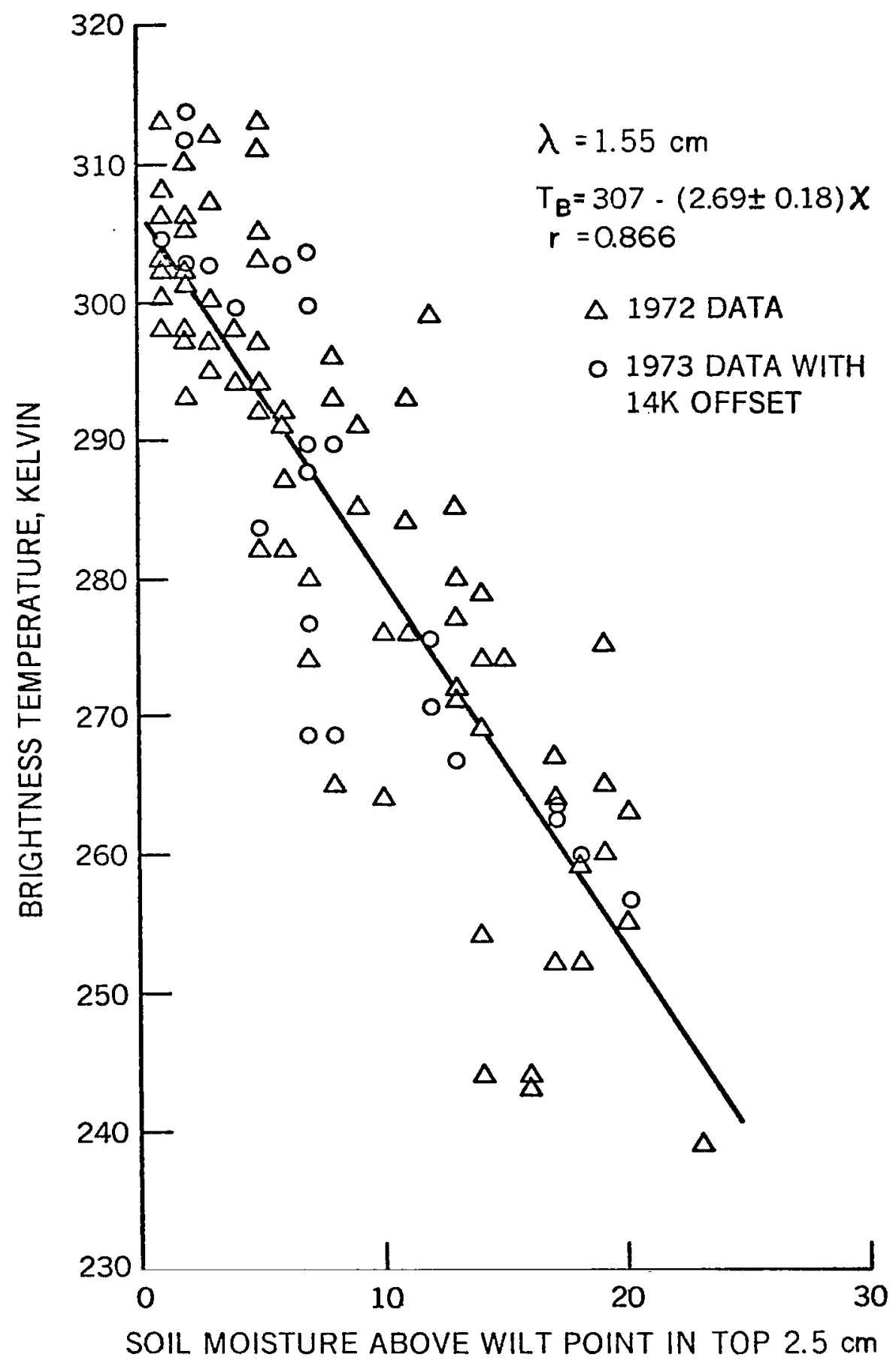

Figure 9 . $1.55-\mathrm{cm}$ brightness temperatures versus the soil moisture above the wilt ,point for the soil. 


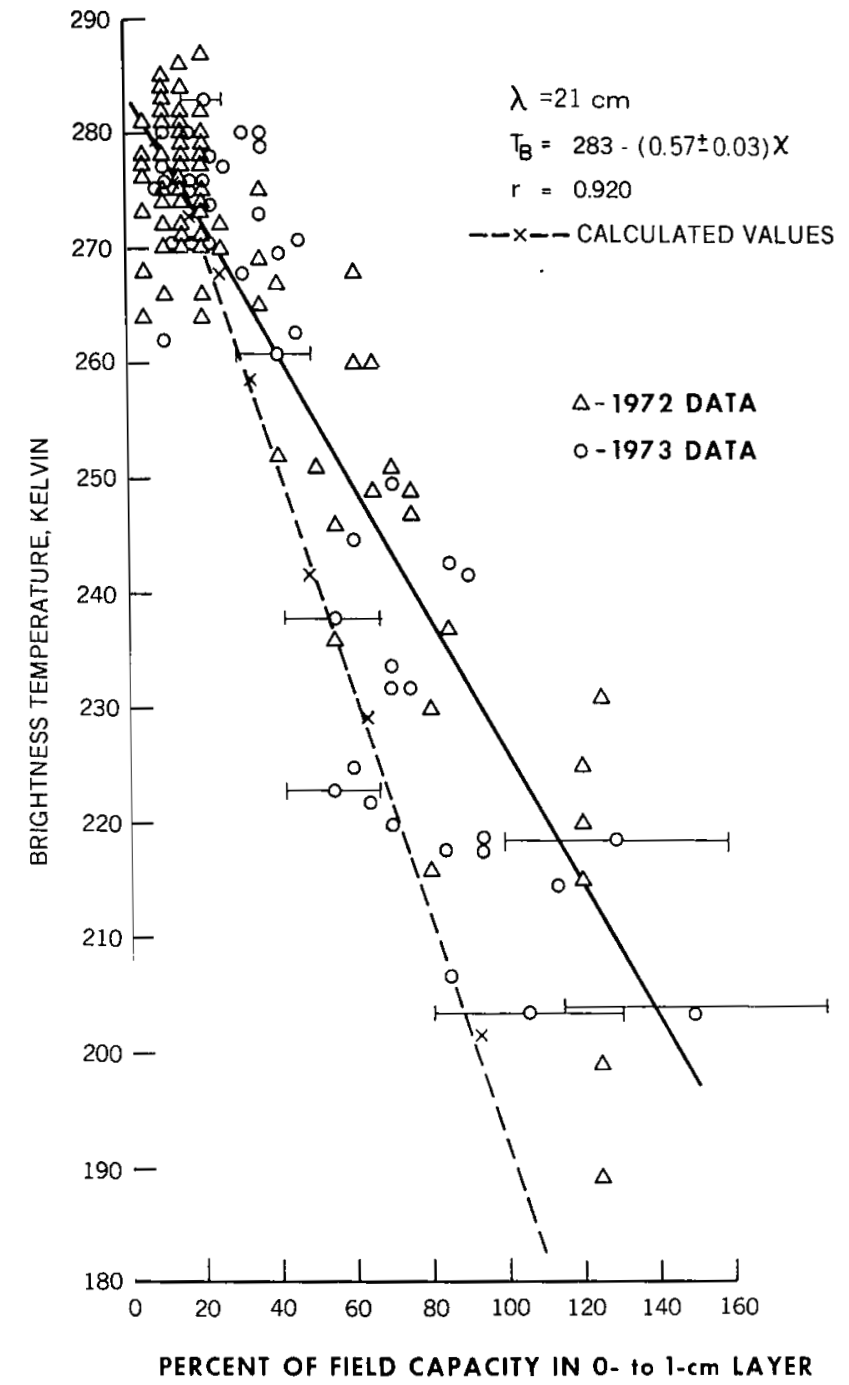

Figure $10.21-\mathrm{cm}$ brightness temperatures versus percent of field capacity in the $0-$ to $1-\mathrm{cm}$ soii layer.

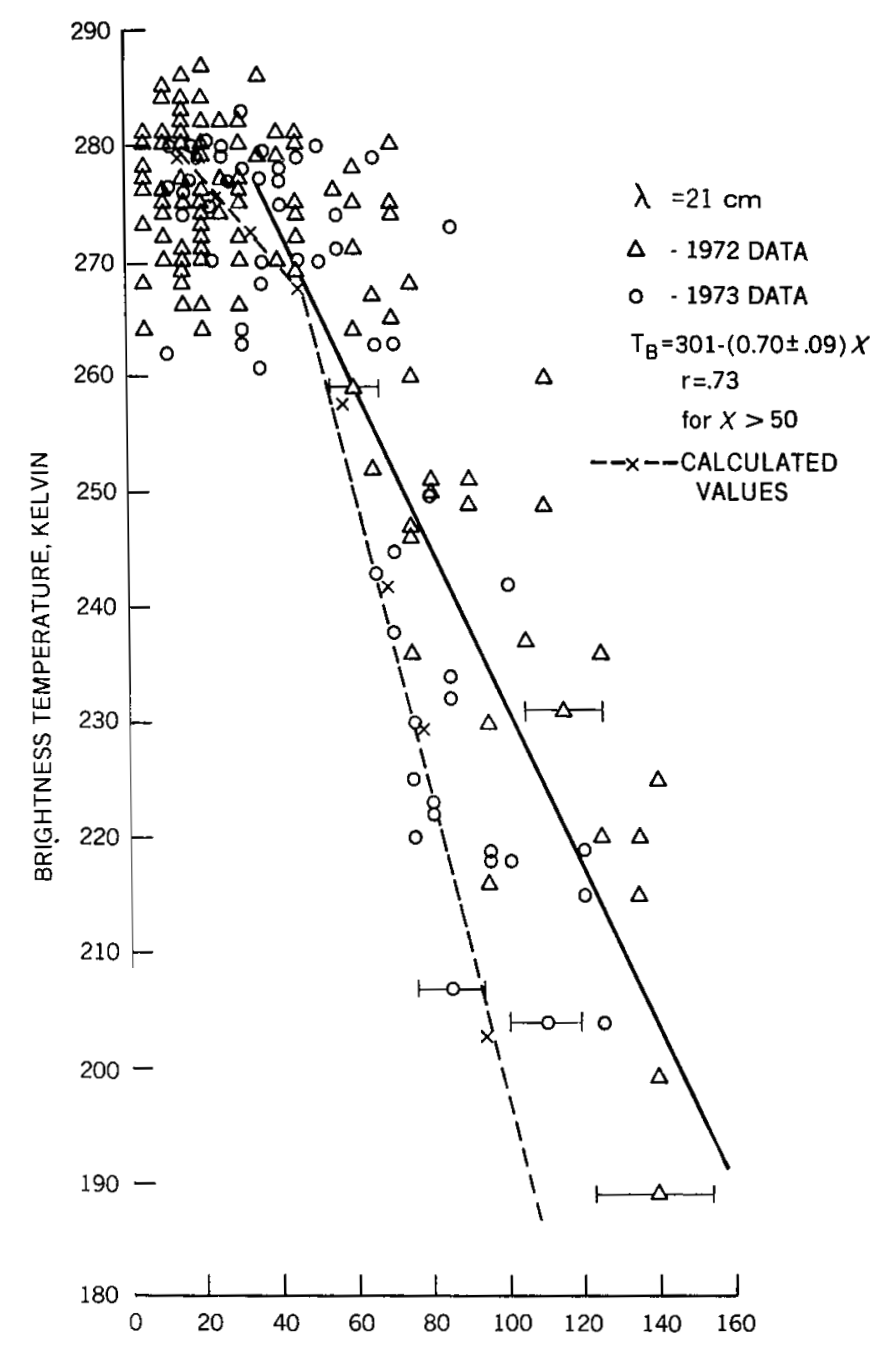

PERCENT OF FIELD CAPACITY IN 0 - to $2.5-\mathrm{cm}$ LAYER

Figure 11. 21-cm brightness temperatures versus percent of field capacity in the $0-$ to $2.5-\mathrm{cm}$ soil layer. 


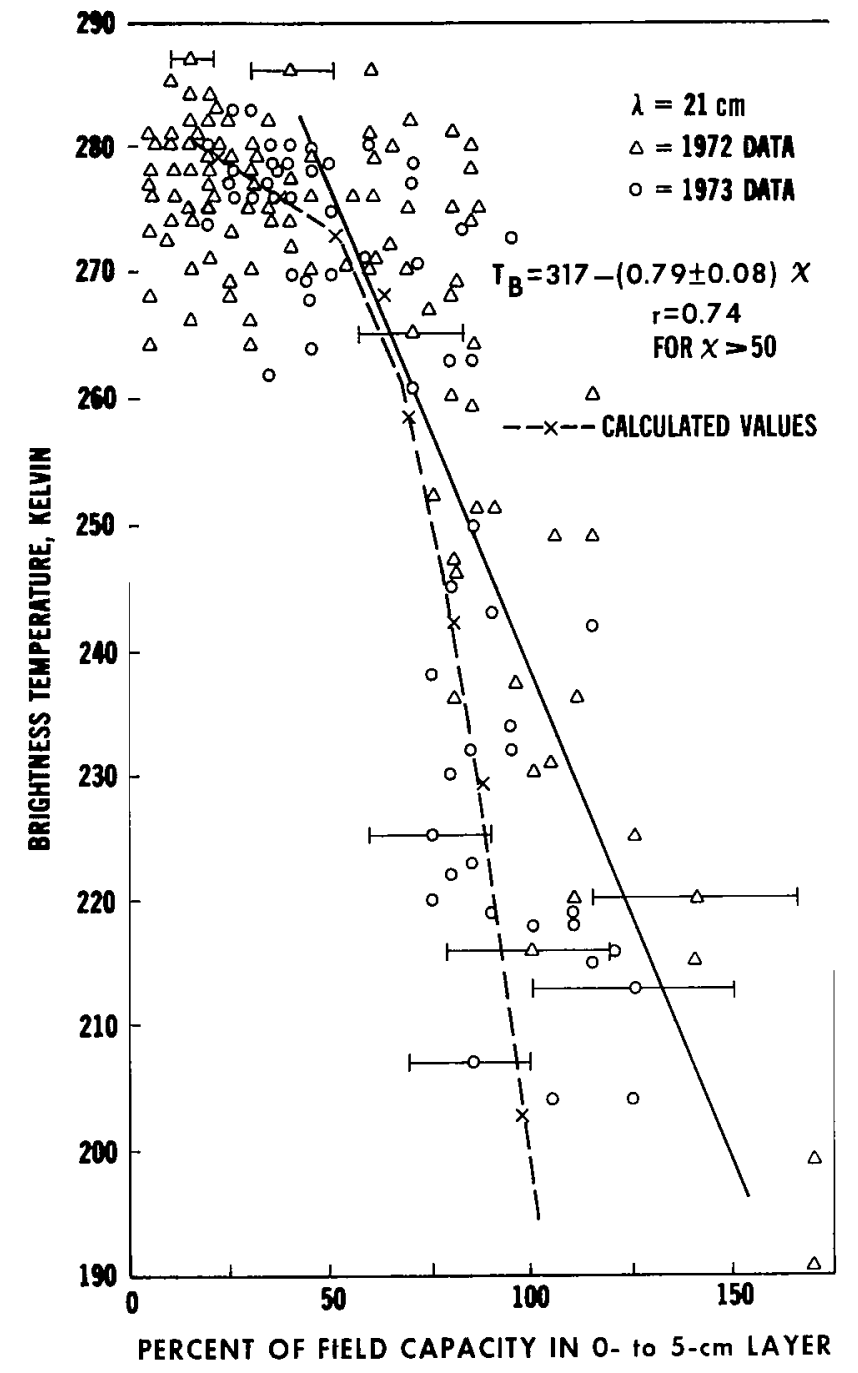

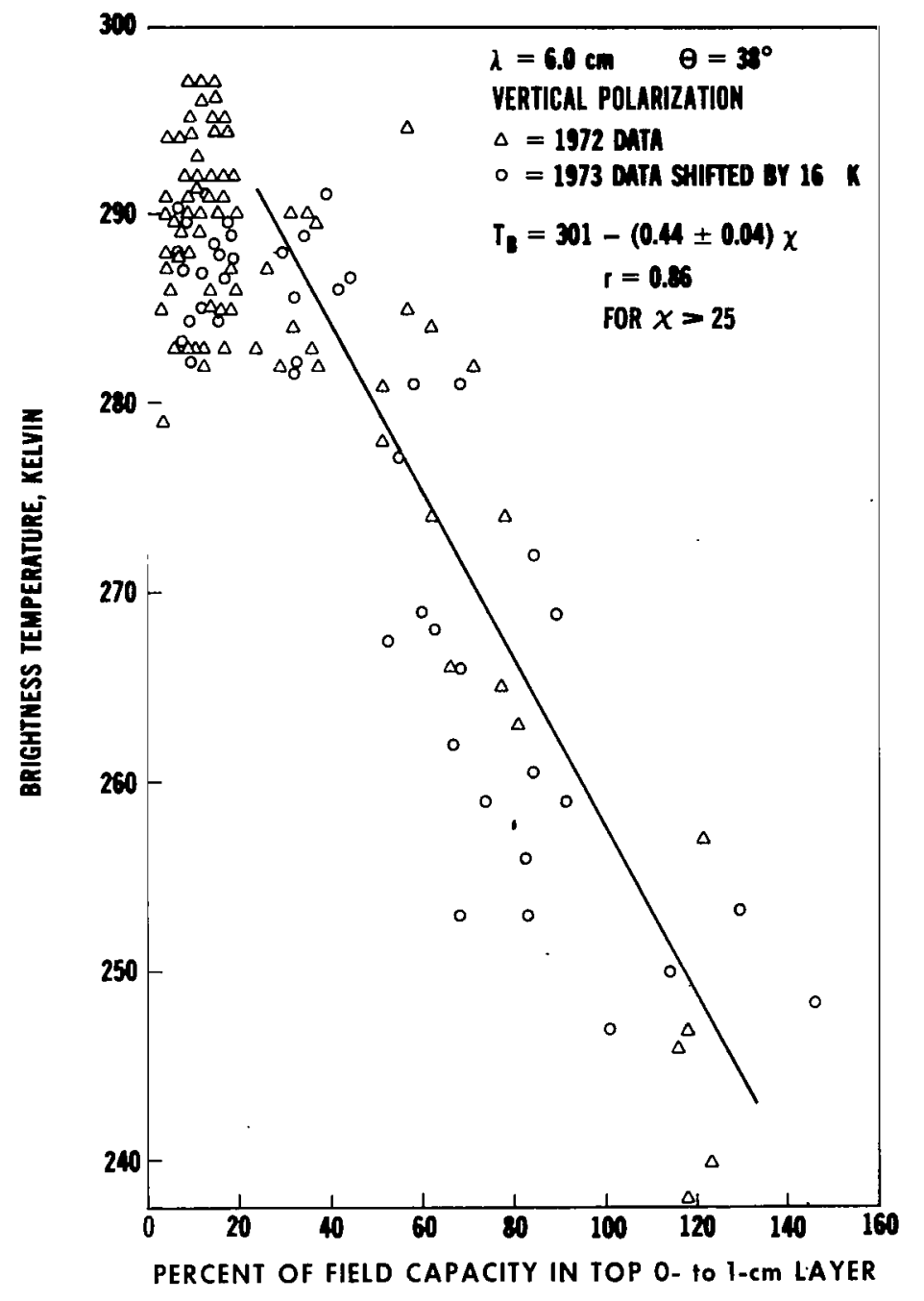

Figure 13. Brightness temperature for the off-nadir $6.0-\mathrm{cm}$ radiometer versus percent of field capacity in the $0-$ to $1-\mathrm{cm}$ soil layer. 


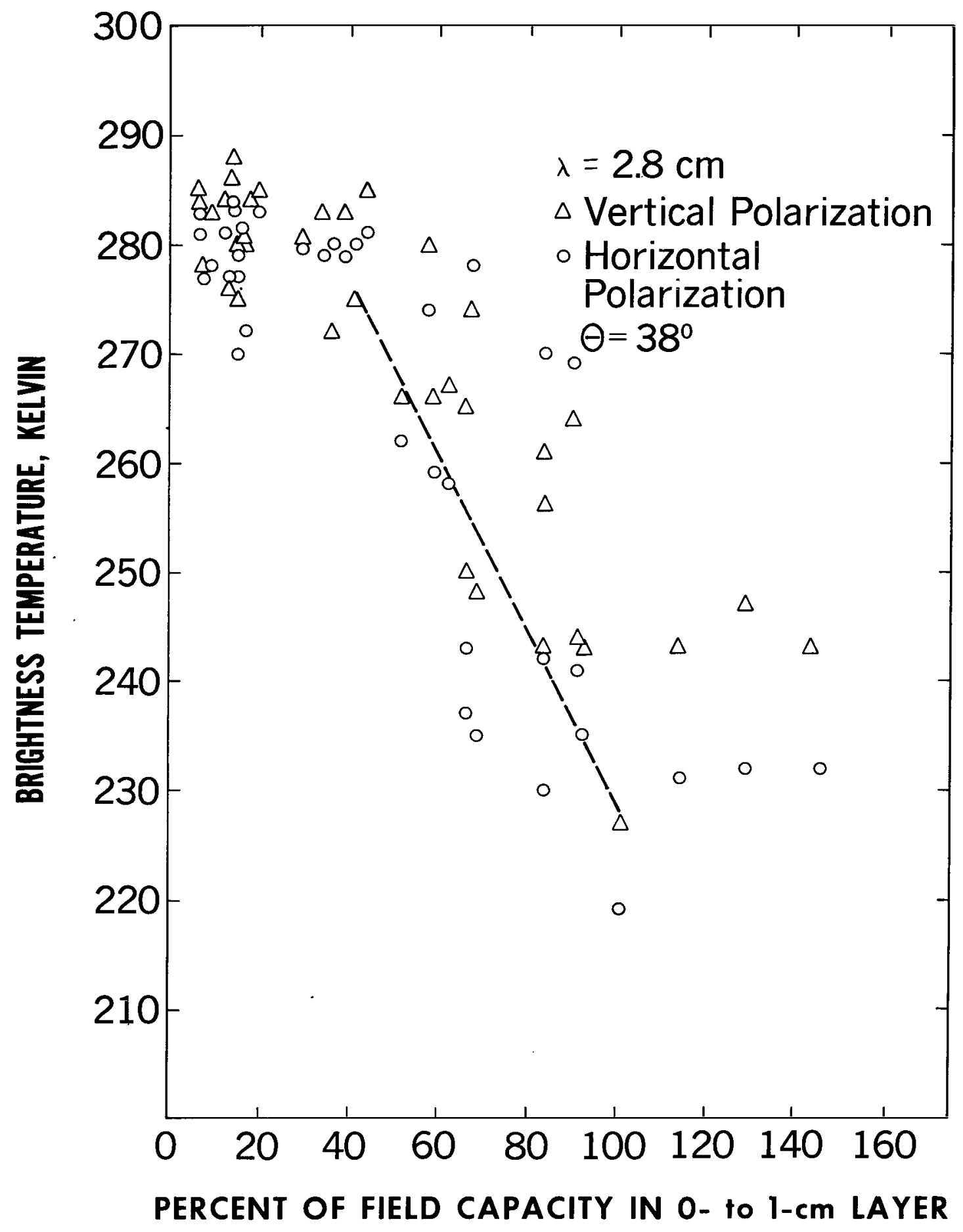

Figure 14. Brightness temperature for the off-nadir $2.8-\mathrm{cm}$ radiometer versus percent of field capacity in the $0-$ to $1-\mathrm{cm}$ soil layer. 


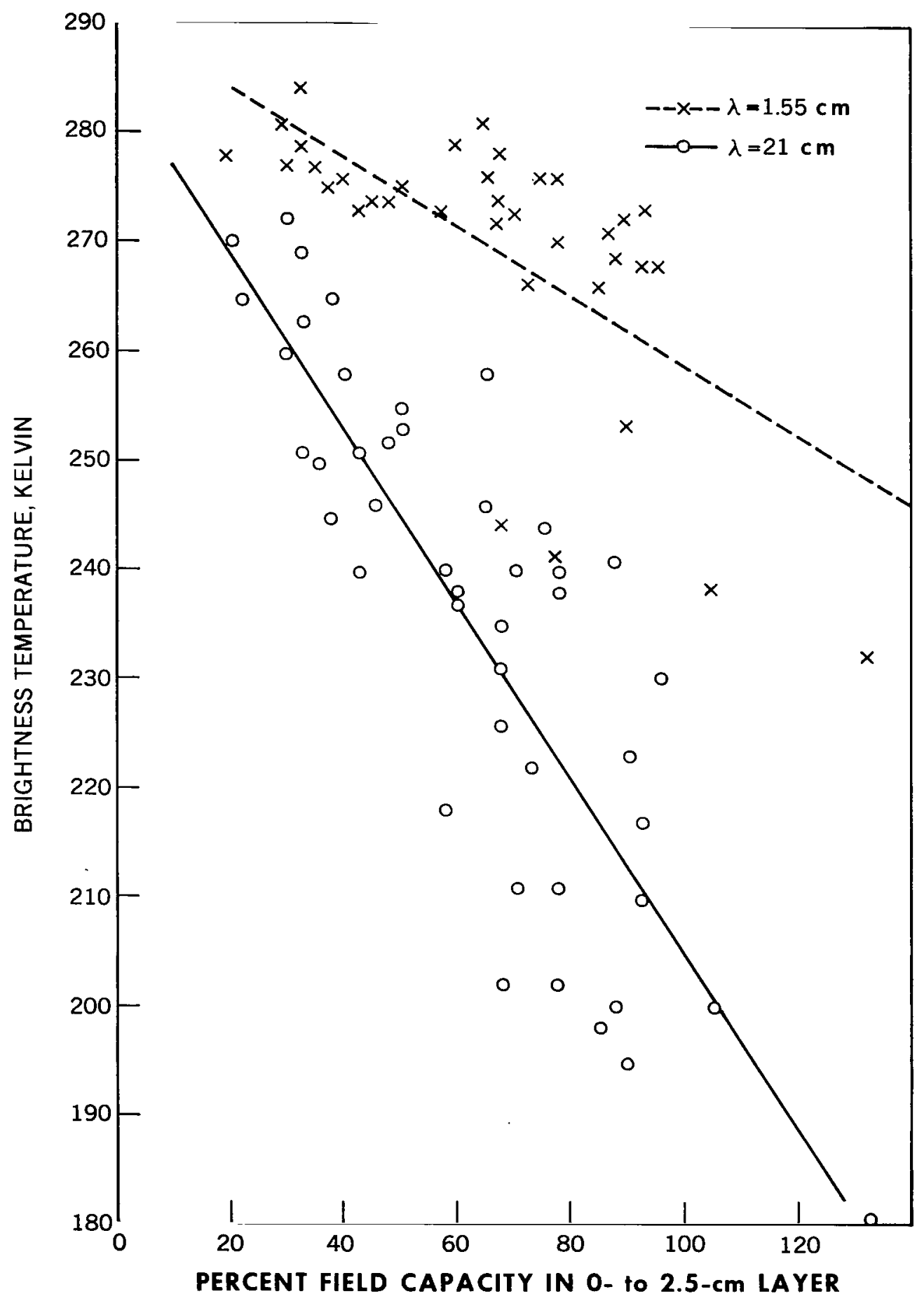

Figure 15. Brightness temperatures for vegetated fields versus percent jof field capacity in in the 0 - to $2.5-\mathrm{cm}$ soil layer. 


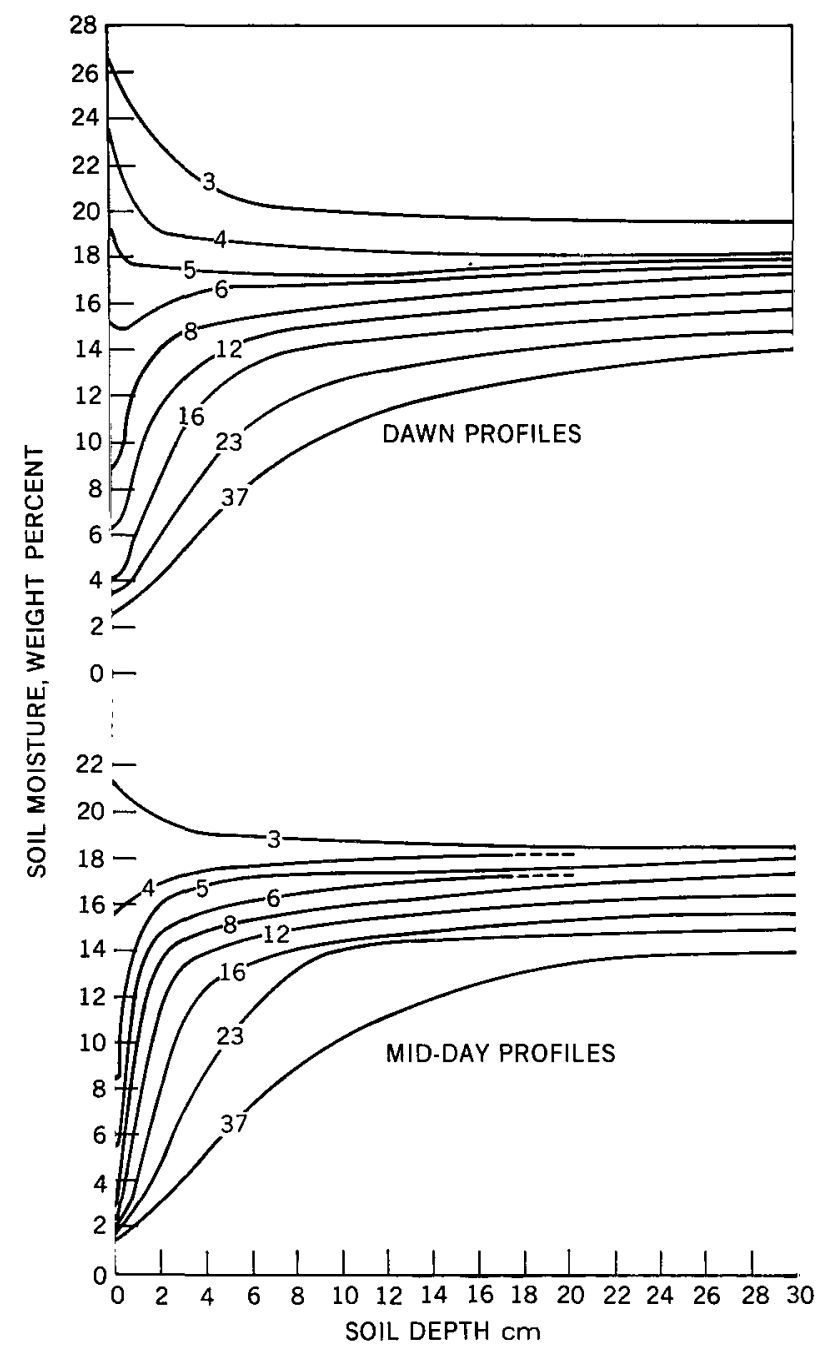

Figure 16. Soil moisture profiles observed at the U.S. Water Conservation Laboratory. The curves are labeled by the number of days after irrigation.

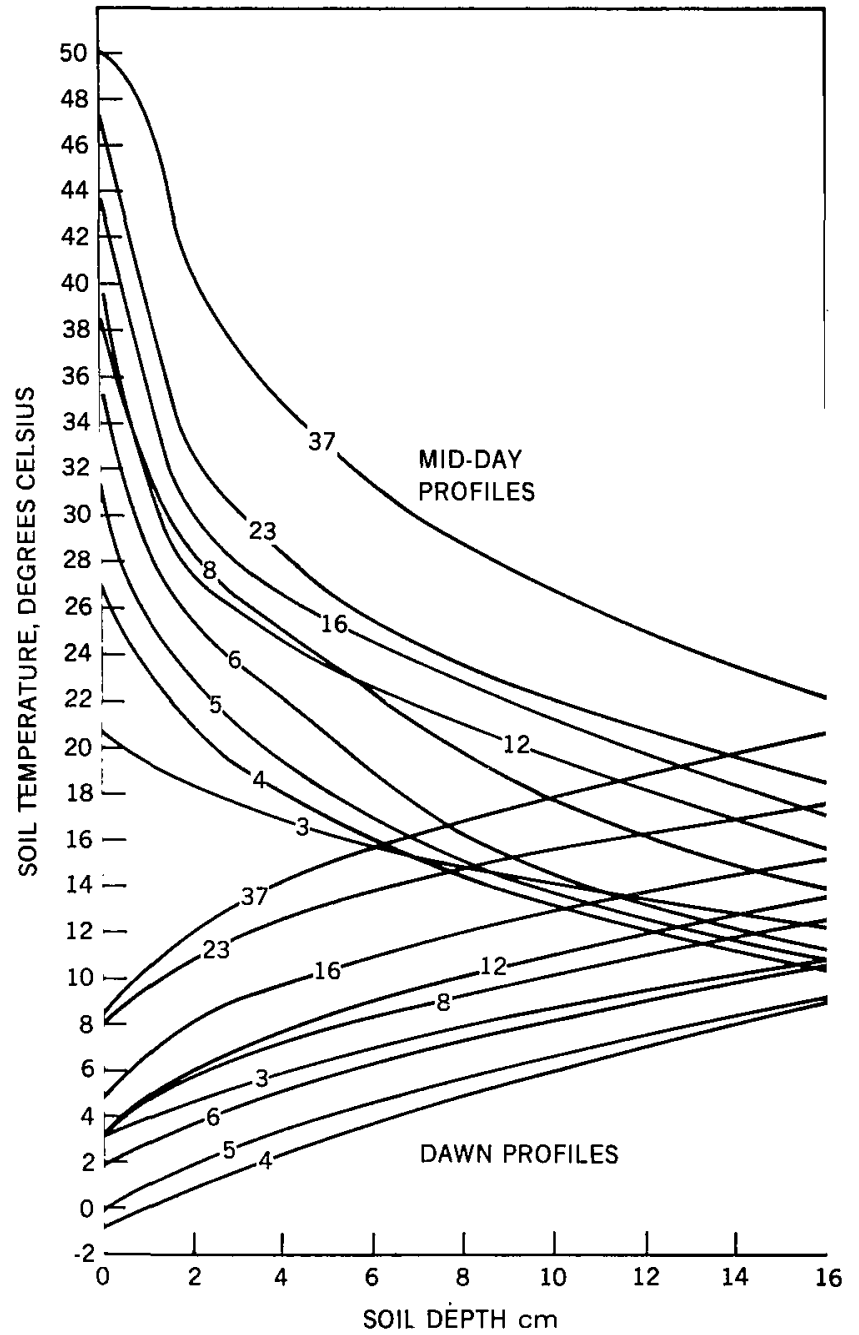

Figure 17. Soil temperature profiles observed during this experiment. 


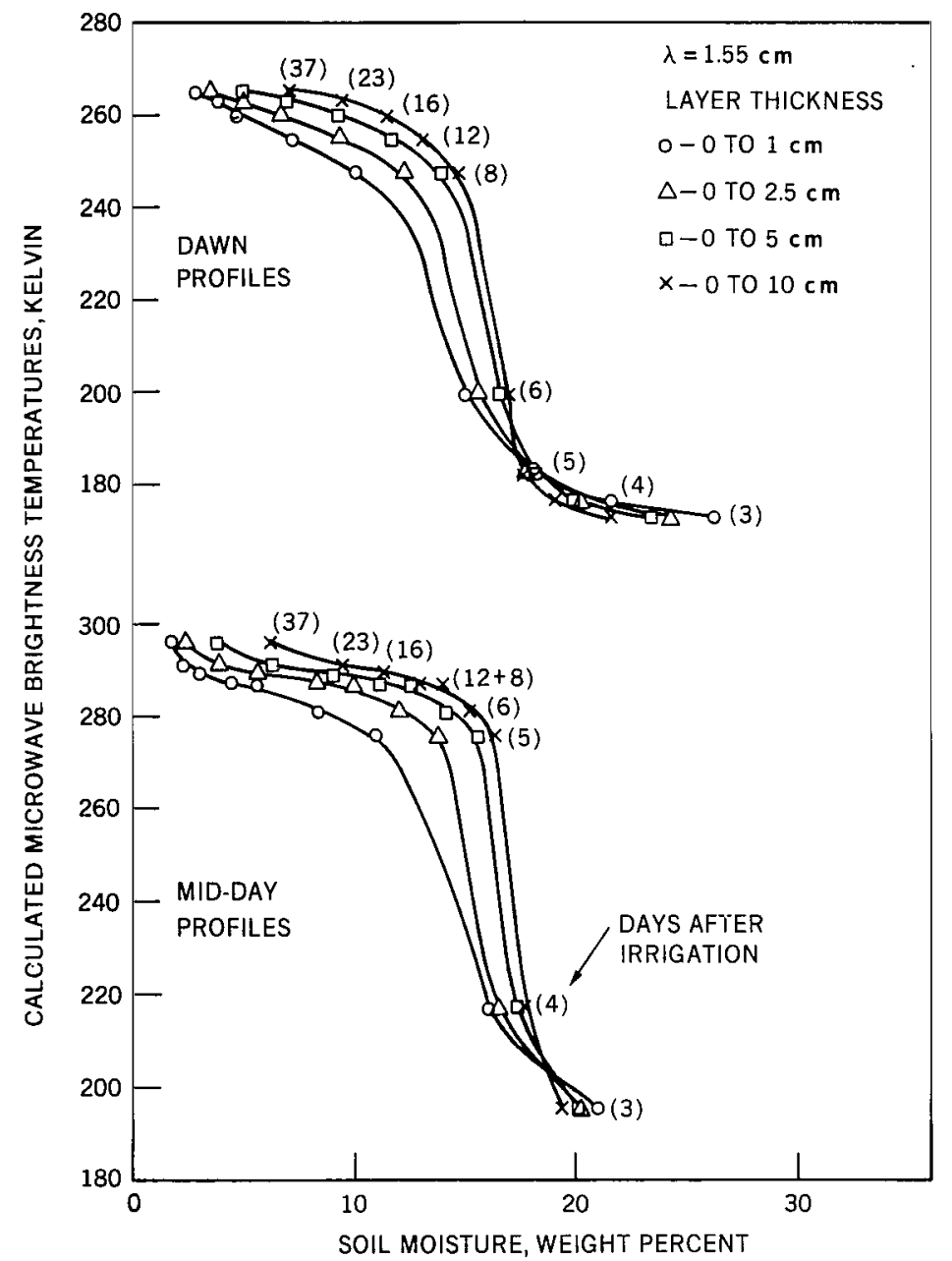

Figure 18. Calculated $\overline{2}-\mathrm{cm}$ brightness temperatures for the

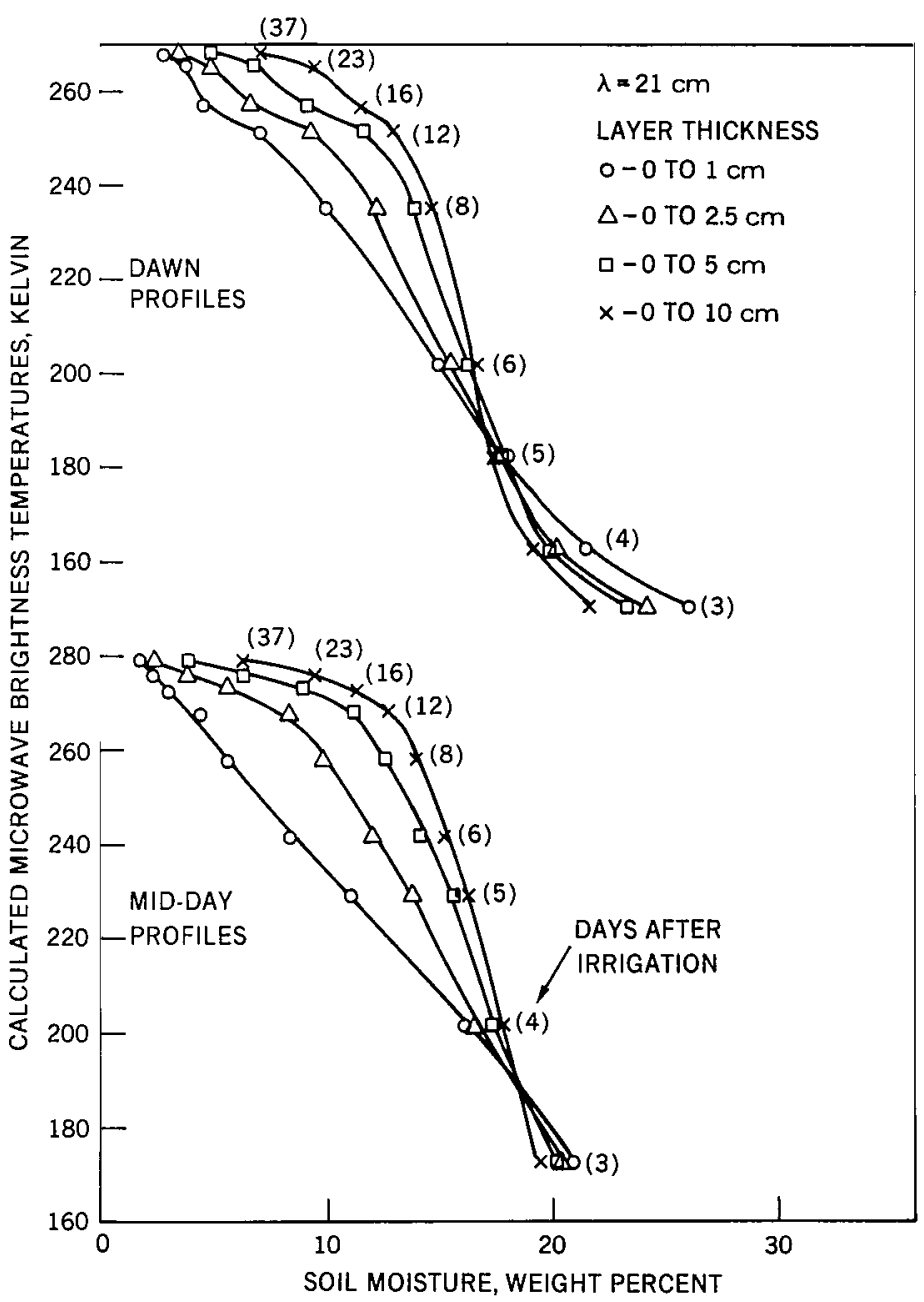

Figure 19. Calculated $1.55-\mathrm{cm}$ brightness temperatures for the profiles presented in figures 16 and 17. age soil moisture in the $0-$ to $1-$, to $2.5-, 0-$ to $5-$, and $0-$ to $10-\mathrm{cm}$ layers. 


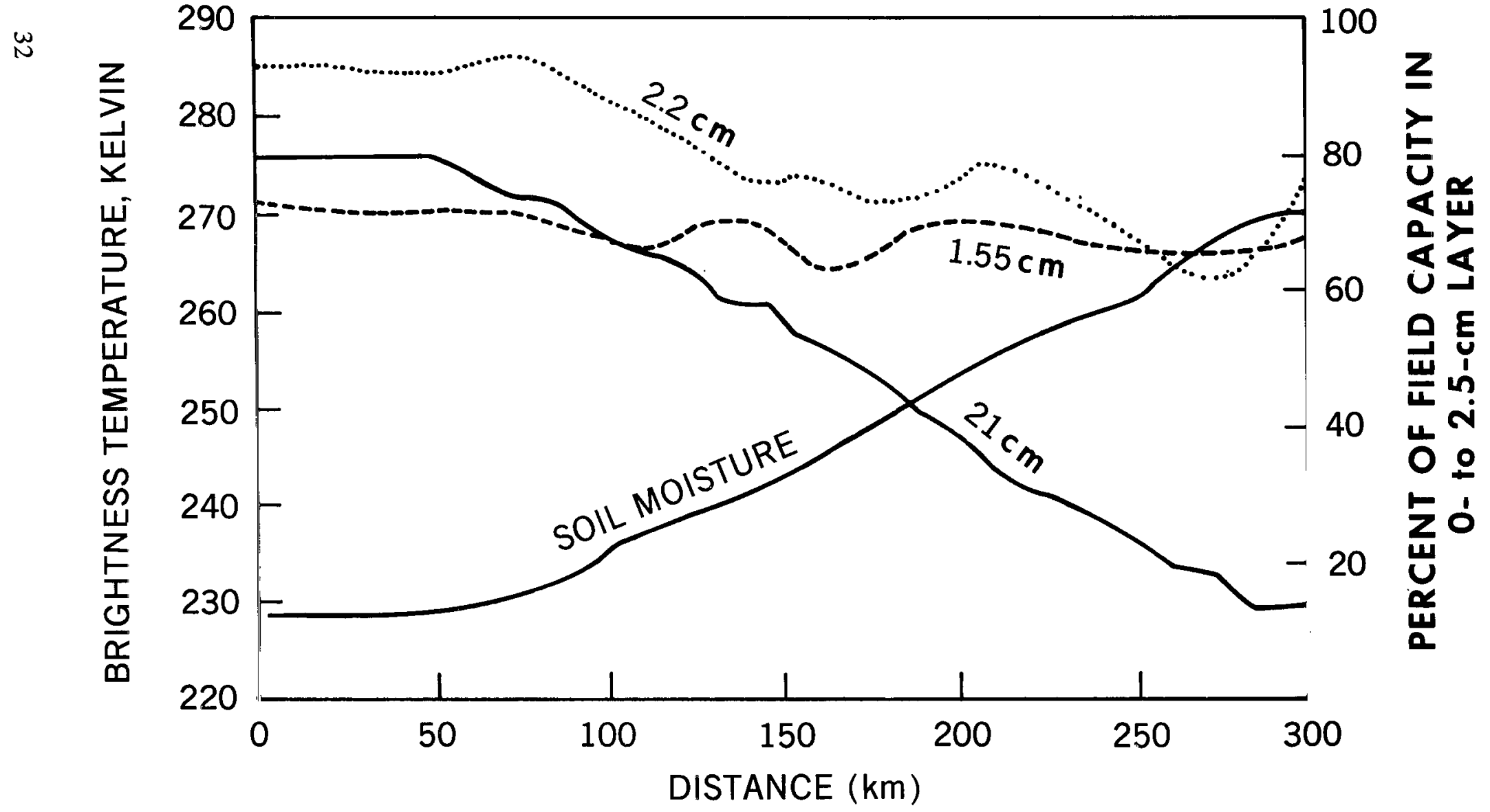

Figure 20. Variations of the Skylab 2.2-cm and 21-cm (Reference 25) and the Nimbus-5 1.55-cm brightness temperatures for a 300-km swath across north central Texas on June 5, 1973. 


\section{REFERENCES}

1. Idso, S. B., R. D. Jackson, and R. J. Reginato, "Detection of Soil Moisture by Remote Surveillance," American Scientist, 63, 1975, pp. 549-557.

2. Idso, S. B., R. D. Jackson, R. J. Reginato, B. A. Kimball, and F. S. Nakayama, "The Dependence of Bare Soil Albedo on Soil Water Content," J. Appl. Meteorology, 14, 1975, pp. 109-113.

3. Idso, S. B., T. J. Schmugge, R. D. Jackson, and R. Reginato, "The Utility of Surface Temperature Measurements for the Remote Sensing of Soil Water Status," J. Geophys. Res., 80, 1975, pp. 3044-3049.

4. Ulaby, F. T., J. Cihlar, and R. K. Moore, "Active Microwave Measurements of Soil Water Content," Remote Sensing of Environment, 3, 1974, pp. 185-203.

5. Schmugge, T., P. Gloerson, T. Wilheit, and F. Geiger, "Remote Sensing of Soil Moisture with Microwave Radiometers," J. Geophys. Res., 79, 1974, pp. 317-323.

6. Poe, G., A. Stogryn, and A. T. Edgerton, Determination of Soil Moisture Content Using Microwave Radiometry, final report 1684FR-1 DOC contract 635239, Aerojet-General Corp., Microwave Division, El Monte, Calif., 1971.

7. Lee, S. L., Dual Frequency Microwave Radiometer Measurements of Soil Moisture for Bare and Vegetated Rough Surfaces, Technical Report RSC-56, Remote Sensing Center, Texas A\&M University, College Station, Texas, August 1974.

8. Basharinov, A. Ye., L. F. Borodin, and A. M. Shutko, "Superhigh Frequency Radiation Characteristics of Wet Soils," (Report presented at the Soviet-American Working Group on the Study of Natural Resources of the Earth), April 1974, NASA TT F-15, pp. 501.

9. Lane, J. A. and J. A. Saxton, "Dielectric Dispersion in Pure Polar Liquids at Very High Radio-Frequencies, Measurements on Water, Methyl and Ethyl Alcohols," Proc. Roy. Soc., A 213, 1952, pp. 400-408.

10. Lundien, J. R., Terrain Analysis by Electromagnetic Means, Technical Report No. 3-693, Report 5, U.S. Army Waterways Experiment Station, Vicksburg, Mississippi, 1971.

11. Jackson, John D., Classical Electrodynamics, New York, New York, 1962.

12. Hoekstra, P. and A. Delaney, "Dielectric Properties of Soils at UHF and Microwave Frequencies," J. Geophys. Res., 79, 1974, pp. 1699-1708.

13. Wilheit, T., Radiative Transfer in a Plane Stratified Dielectric, NASA TM X-71051, March 1975. 
14. Salter, P. J. and J. B. Williams, "The Influence of Texture on the Moisture Characteristics of Soil," J. Soil Sci., 20, 1969, pp. 126-131.

15. Heilman, M. D., J. R. Thomas, D. L. Carter, and C. M. Thompson, Chemical, Physical and Mineralogical Characteristics of Eight Irrigated Soils of the Lower Rio Grande Valley of Texas, SWC Research Project 382, USDA-ARS Soil and Water Conservation Research Division, Weslaco, Texas, 1966.

16. Sibley, T.G., Microwave Emission and Scattering from Vegetative terrain, Remote Sensing Center, Texas A\&M University, College Station, Texas, August 1973.

17. National Aeronautics and Space Administration, Airborne Microwave Radiometric Data Final Report, Part II, Analysis Contract No. NAS 5-21674, Biospherics, Inc., June 1972.

18. Reynolds, S. C., "The Gravimetric Method of Soil Moisture Determination, Part II, Typical Required Sample Sizes and Methods of Reducing Variability," J. Hydrology, 11, 1970, pp. 274-287.

19. Schmugge, T., B. Blanchard, W. Burke, J. Paris, and J. Wang, Results of the April 1974, Soil Moisture Flight, NASA TN D-8199, 1976.

20. Jackson, R. D., R. J. Reginato, and S. B. Idso, "Timing of Ground Truth Acquisition During Remote Assessment of Soil-Water Content," Remote Sensing of the Environment, 4, 1976, pp. 249-255.

21. Kuhn, P. M., M. S. Lojko, and E. V. Peterson, "Water Vapor; Stratospheric Injection by Thunderstorms," Science, 174, 1971, p. 1319.

22. Burke, W. J. and J. F. Paris, "A Radiative Transfer Model for Microwave Emission from Bare Agricultural Soils," NASA TM X-58166, August 1975.

23. Jackson, R. D., Diurnal Soil-Water Content Changes During Drying, Field Soil Water Regime, SSSA Special Publication No. 5, Soil Science Society of America, Madison, Wisconsin, 1973, pp. 37-56.

24. Eagleman, J. R. and W. C. Lin, "Soil Moisture Detection from Skylab," (Proceedings of the NASA Earth Resources Symposium, Houston, Texas), NASA TM X-58168, June 1975, pp. 2233-2241.

25. MacFarland, M. J., "The Correlation of Skylab L-Band Brightness Temperatures with Antecedent Precipitation," (Proceedings of the NASA Earth Resources Symposium, Houston, Texas), NASA TM X-58168, June 1975, pp. 2243-2252. 


\author{
$748001 \mathrm{CH}$ O E $76 \mathrm{Cg} 03$ S00903DS \\ DEET CF THE AIE FCBCE \\ AF WEAPCNS IABCEATOEY \\ TTTN: TECHNICAI. IIBFAEY \\ KIRTIANL AFE NM 87117

"The aeronautical and space activities of the United States shall be conducted so as to contribute ... to the expansion of buman knowledge of phenomena in the atmosphere and space. The Administration shall provide for the widest practicable and appropriate dissemination of information concerning its activities and the results thereof."

-National Aeronautics and Space ACt of 1958

\title{
NASA SCHENTIFIC AND TECHNICAL PELICATIONS
}

TECHNLCAL RERORTS Scientific and technical information considered important, complete, and a lasting contribution to existing knowledge.

TECHNICAL NOTES: Information less broad in scope but nevertheless of importance as a contribution to existing knowledge. , ,... ? TECHÑICAL MẾOORANONUMS:

Information receiving limited distribution because of preliminary data, security classification, or other reasons. Also includes conference proceedings with either limited or unlimited distribution.

CONTRACTOR REPORTS: Scientific and technical information generated under a NASA contract or grant and considered an important contribution to existing knowledge.
TECHNICAL TRANSLATIONS: Information published in a foreign language considered to merit NASA distribution in English.

SPECIAL PUBLICATIONS: Infformation derived from or of value to NASA activities. Pubblications include final reports of major projects, monographs, data compilations, handbooks, sourcebooks, and special bibliographies.

\section{TECHNOLOGY UTILIZATION} PUBLICATIONS: Information on technology used by NASA that may be of particular interest in commercial and other non-aerospace applications. Publications include Tech Briefs, Technology Utilization Reports and Technology Surveys.

Defails on the availability of these publications may be obfained from:

SCIENTIFIC AND TECHNICAL INFORMATION OFFICE 